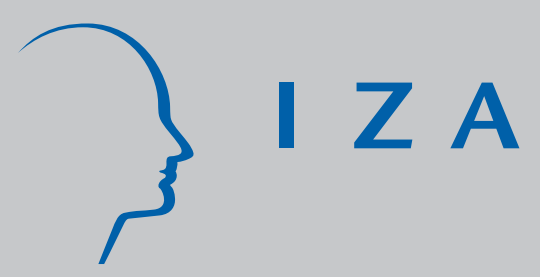

IZA DP No. 2864

Gross Worker Flows in the Presence of Informal Labor Markets: Evidence from Mexico, 1987-2002

Mariano Bosch

William Maloney

J une 2007 


\title{
Gross Worker Flows in the Presence of Informal Labor Markets: Evidence from Mexico, 1987-2002
}

\author{
Mariano Bosch \\ London School of Economics
}

William Maloney

World Bank and IZA

Discussion Paper No. 2864

June 2007

IZA

P.O. Box 7240

53072 Bonn

Germany

Phone: +49-228-3894-0

Fax: +49-228-3894-180

E-mail: iza@iza.org

\begin{abstract}
Any opinions expressed here are those of the author(s) and not those of the institute. Research disseminated by IZA may include views on policy, but the institute itself takes no institutional policy positions.

The Institute for the Study of Labor (IZA) in Bonn is a local and virtual international research center and a place of communication between science, politics and business. IZA is an independent nonprofit company supported by Deutsche Post World Net. The center is associated with the University of Bonn and offers a stimulating research environment through its research networks, research support, and visitors and doctoral programs. IZA engages in (i) original and internationally competitive research in all fields of labor economics, (ii) development of policy concepts, and (iii) dissemination of research results and concepts to the interested public.
\end{abstract}

IZA Discussion Papers often represent preliminary work and are circulated to encourage discussion. Citation of such a paper should account for its provisional character. A revised version may be available directly from the author. 


\section{ABSTRACT \\ Gross Worker Flows in the Presence of Informal Labor Markets: Evidence from Mexico, 1987-2002*}

This paper applies recent advances in the study of labor market dynamics to a representative developing country with a large unregulated of "informal" sector. It confirms the relevance of the recent mainstream models and debates surrounding gross worker flows to the developing country context, and offers a new view of the role of the informal sector and its role in labor market adjustments. It finds, first, that the formal salaried sector shows the same procyclical job finding rate and mildly countercyclical separation behavior identified in the recent US literature by Shimer (2005a) and Hall (2005). The unregulated informal sector, however, shows reasonable acyclicality in the job finding rate coupled with sharp countercyclical movements in the job separation rate, consistent with standard small firm dynamics and Davis and Haltiwanger (1992 and 1999). The differential behavior of regulated and unregulated sectors, and the finding of relative wage rigidity in the former, sheds suggestive light on the debate surrounding countercyclical job finding behavior in the US. Second, the patterns of worker transitions between all sectors, formal and informal correspond to the jobto-job dynamics observed in the US and not to the traditional idea of informality constituting the inferior sector of a segmented market. That said, the counter cyclical job finding in the formal sector combined with the acyclical job finding in informality does lead to the latter absorbing relatively more labor during downturns, even as its increased separation rates drive movements in unemployment.

JEL Classification: J41, J42, J6

Keywords: $\quad$ gross worker flows, labor market dynamics, informality

Corresponding author:

William F. Maloney

The World Bank

1818 H St. NW

Washington, D.C. 20433

USA

E-mail: wmaloney@worldbank.org

\footnotetext{
* We are very grateful to Christopher Pissarides for invaluable comments, Carlos Arango for advice in the early phases of this project, and to Lucas Siga for help in managing the data.
} 


\section{Introduction}

This paper applies recent advances in the study of labor market dynamics over the business cycle to Mexico. The analysis is of broad interest in three respects. First, the structure of the Mexican labor market is broadly representative of those found in many developing countries. The analysis of labor force dynamics here, the first to our knowledge for the developing world, provides insights into the functioning of the primary income source of the world's poor and the roots of their often high rates of unemployment. Second, perhaps most emblematic of these markets is a large informal or unregulated micro-firm sector that has been the subject of thirty years of debate over its nature: disadvantaged sector of a highly segmented labor market (effectively disguised unemployment) vs simply an enlarged, relatively voluntary micro-firm sector that, for a variety of reasons, interacts little with formal institutions. Finally, studying the differing dynamics of regulated and unregulated salaried sectors sheds some suggestive light on the recent debate surrounding the cyclical dynamics of the US labor market, and the appropriate models to analyze them.

\section{Background}

A central underlying theme of the paper is the necessity of locating the analysis of developing country labor markets within the frontier literature on gross labor flows and the surrounding debates. In one of the first works in this area, Blanchard and Diamond (1990) argued that slowdowns of the economy are characterized by a significant increase in the number of workers transitioning from employment into unemployment. Consistent with this, Davis and Haltiwanger (1990 and 1992) in a series of papers using establishment data showed that job destruction is countercyclical. Both sets of findings constituted empirical support for the predominant search and matching models in the Mortensen and Pissarides tradition. ${ }^{1}$ However, recently Shimer (2005b) and Hall (2005) have argued that, in fact, job separations are largely acyclical, while the finding rate is

\footnotetext{
${ }^{1}$ See Mortensen Pissarides (1994, 1999a and 1999b), Pissarides (2000) and Rogerson, Shimer and Wright (2005) for a review of these models and their implications.
} 
highly procyclical. That is, contrary to the conventional wisdom, unemployment rises because jobs become hard to find, not because they are destroyed. Further, Shimer (2005b) argues that the response of vacancies and unemployment to productivity shocks predicted by a standard search model explains only around $10 \%$ of the observed volatility of the job finding rate. Explaining these stylized facts, Shimer (2005b) and Hall (2005) argue, requires introduc ing wage rigidities into standard matching models.

Davis et al. (2005) rejoin that the observed cyclical patterns are in fact rooted in the highly non-linear micro-relations they find between firm growth and job growth. Patterns of gross job flows depend on the particular movements in the cross sectional density of firms during the downturn, and in particular, the incidence of firm failure. ${ }^{2}$ This, in turn, suggests that dynamics depend on the cross-sectional density of firm size itself as it is highly correlated with mortality. Boeri (1996), in fact, argues that the documented countercyclical patterns of job turnover in the US, unique among advanced country labor markets, appear driven largely by the lack of coverage in the US data of firms of under 5 workers. ${ }^{3}$

Mexico is not unusual among developing countries in having roughly half of the workforce employed in such small firms and hence we may expect to find aggregate labor force dynamics that differ from those found in the US for this reason alone. In addition, however, most of these workers are informal and uncovered by standard labor protections. Having in our sample at once a salaried sector similar to that in advanced countries, as well one relatively unaffected by unionization or minimum wage legislation thus offer potentially informative insights into Shimer's and Hall's hypotheses about the impact of wage rigidities on patterns of job finding and separation rates. Of more direct

\footnotetext{
${ }^{2}$ In the US more than two-thirds of job destruction occurs at establishments that shrink by more than $10 \%$ within a quarter and more than a fifth in firms that go to zero unemployment. These can lead to a dominant role for the job finding rate in explaining unemployment movements in mild downturns such as the most recent one US, and a larger role for job loss in severe downturns where more firms go bankrupt.

${ }^{3}$ Although such firms account for less than $5 \%$ of employment, they typically account for a very large component of total gross job flows- in western Germany, they account for more than 50\% of turnoverconsistent with standard findings, dating from Dunne, Roberts and Samuelson (1989), that small firms have very high mortality rates. See Jovanovic (1982), Pakes and Ericson (1992,1995) for models of firm dynamics that explain the higher mortality rates of small firms.
} 
importance to developing countries, the dynamic patterns we document weigh in, we think definitively, on the sharp debate in the literature surround ing what the existence of the unprotected sector implies about the structure of LDC labor markets. The dominant perspective with intellectual roots dating at least from Harris and Todaro (1973), equates the sector with underemployment or disguised unemployment- the disadvantaged sector of a market segmented by rigidities in the "formal" or covered sector of the economy. However, another emerging view keys more off the mainstream self-employment literature in the style of Lucas (1978), Jovanovic (1982) and Evans and Leighton (1989), and argues that, as a first approximation, the sector should be seen as an unregulated, largely voluntary self-employed/micro-firm sector. ${ }^{4}$

While the informal sector in all likelihood contains both types of actors, disguised unemployed and entrepreneurial, its exaggerated size in developing countries raises the stakes surrounding the relative proportions dramatically: If the roughly 35-60 percent of the Latin American workers found in the informal sector show dynamics similar to those of the unemployed, then the labor market distortions in the formal sector are indeed large and the case for massive reform, compelling. However, should the dynamics correspond more to a voluntary small firm sector that offers an alternative, but not obviously inferior income source, then, aggregate labor force dynamics may differ fom what has been found in the US, but not pathologically so.

To capture and formalize these dynamics, we introduce recent techniques for estimating labor market transitions in a continuous time context, and employ the advances by Shimer for explaining the movements in unemployment shares in the US. We are able to study labor force dynamics across two recoveries and two recessions, one being the celebrated Tequila crisis of 1995-96. This offers a useful laboratory for studying how the various sectors adjust not just across the business cycle but also, as suggested by Davis et. al, how dynamics may change depending on the nature and magnitude of the shock.

\footnotetext{
4 Elements of this view are found in de Soto's celebrated The Other Path (1989). For a review of the literature and early work on transition matrices in developing country see Maloney $(1999,2005)$
} 
As a brief foreshadowing of the results, we show first, that the debate over the role of the informal sector in developing country labor markets is, in fact, closely related to the debate in the mainstream literature over how the OECD labor market adjusts across the business cycle, and that mainstream theoretical models are very relevant to the developing country context. The dynamics of the formal salaried sector in Mexico correspond closely to Shimer's US patterns of constant job separation rates, but varying job finding rates. The dynamics of the informal micro-firm sector correspond more to the Haltiwanger et al. view where the reverse is true. As suggestive support for a Hall-Shimer explanation of this differing behavior, we establish that there is more wage flexibility in the informal sectors than in the formal salaried sectors and that the observed movements in relative wages correspond reasonably well to movements in relative job finding rates across the sectors.

Second, putting the distinct job finding behaviors together gives a view of labor market adjustment in LDCs across the business cycle that has elements of the traditional view of the role of informality across downturns, but perhaps with an updated mechanism, and without a connotation of overall inferiority of the sector. Transitions among all sectors, formal and informal, are broadly pro-cyclical and highly correlated with each other, providing some of the strongest evidence that most transitions into informality correspond to job-to-job transitions in the mainstream literature, and not into disguised unemployment. However, during downturns, the formal salaried sector stops creating new jobs, as is the case in the US, but, net, the informal sector does not, even as its increased separation rate drives the increased rates of unemployment.

The next section discusses the data and sectoral definitions. Section III discusses the methodology for estimating the continuous time markov processes underlying the analysis. Section IV presents the main features in the Mexican labor market between 1987 and 2002 and in particular movements in the labor force shares of each employment category across the business cycle. Section V analyzes the gross flows of workers by 
sector and speculates on what may explain the differing patterns observed. Section VI studies the contribution of these flows to the changes in labor force shares identified in section II. Section VII concludes.

\section{Data}

The data for the paper are drawn from the National Urban Employment Survey (ENEU) that conducts extensive quarterly household interviews in the 16 major metropolitan areas. The questionnaire is extensive in its coverage of participation in the labor market, wages, hours worked, etc. that are traditionally found in such employment surveys. The ENEU is structured so as to track a ffth of each sample across a five quarter period. We have concatenated panels from the first quarter of 1987 to the fourth quarter of 2002. Each individual contributed with four transition pairs. In constructing each quarterly pair, we lose roughly $10 \%$ of the sample to attrition. Antman and Mckenzie (2005) conclude after careful analysis of the same data that the bias resulting from this attrition is likely to be very small.

The ENEU has suffered only minor modifications during the covered period but it has substantially changed its geographical coverage. From 1988 to 1992 the survey comprised 16 major urban areas. In 199218 more urban areas were introduced and throughout the following years additional cities were included in the sample to reach 44 at the beginning of 1998. We choose to constraint our sample to the original 16 cities although all results are similar with extended the sample. Since man and women show slightly different labor market dynamics due to different attachment to the labor market, we also restrict our sample to male transitions. 


\section{Defining Informality}

There is broad consensus in the literature on the definition of an informal worker. ${ }^{5}$ Generally speaking, formal workers are those working in firms licensed with the government and conforming to tax and labor laws, including minimum wage directives, pension and health insurance benefits for employees, workplace standards of safety etc. The informal workers, on the contrary, are those owners of firms that are largely de linked from state institutions and obligations and their employees who are not covered by formal labor protections. Consensus over the raison d'etre of the sector has proven far more elusive and the debate goes back in one form or another roughly half a century. A prominent stream of the literature has intellectual roots perhaps best distilled in Harrod and Todaro's vision of market segmented by wage setting in the formal sector that leaves the traditional sector rationed out of modern salaried employment. ${ }^{6}$ The view of informal workers as the inferior or excluded segment of a dual labor market became highly influential in the International Labor Organization, its Latin America affiliate, the Latin America Regional Employment Program (PREALC), and the World Bank. ${ }^{7}$ However, dating at least from Hart's (1972) work in Africa, a parallel stream has stressed the sector's dynamism and likely voluntary nature of much of the entry into the sector, analogous to the mainstream literature such as Jovanovic (1982), and Evans and Jovanovic (1989), and Evans and Leighton (1989) .8

Given the large size of the sector, the stakes in terms of policy formulation are very high indeed. If most of the informal sector is in fact rationed out of good jobs, then the implicit labor distortions in the formal sector are very large and the need for regulatory reform, compelling. Further, social policy becomes a fairly straightforward question of offsetting one distortion with transfers to the disadvantaged sector. If, however, the informal sector is best seen as offering jobs with differing packages of

\footnotetext{
${ }^{5}$ For a survey on the methods estimating the size of the informal sector see Schnider and Enste (2000)

6 In fact, in Harrod and Todaro's model, the "traditional" sector was the rural sector disposed to migrate. However, it represents perhaps the first analytically worked out view of the dual labor market and remains highly relevant to the debate over the segmented rural sector.

${ }^{7}$ For early statements, see Sethuraman (1981), Tokman (1978), Mazumdar (1975), respectively.

${ }^{8}$ See for more recent formulations in this vein, de Soto (1989) and Maloney (2004), Fajnzylber, Maloney and Rojas (2005).
} 
characteristics- more flexibility, no boss, evasion of restrictive and inefficient regulation (including costly and badly designed labor protections), ease of free riding on publicly provided goods- and which are equally desirable for the worker at the margin, then the incidence of segmenting labor legislation is in all probability less acute, and the design of social policy requires considering all the incentives and disincentives to participate in one sector or the other.

We broadly follow the ILO in definition by dividing employed workers into three sectors: formal salaried, informal salaried and informal self employed. However, rather than classifying informal as workers in establishments of fewer than 5-10 employees, we classify on the basis of lack of compliance with labor legislation- in particular lack of contributions by the employer to the social security agency, IMSS (or the equivalent for civil servants IMSTS)- as the critical distinguishing characteristic. ${ }^{9}$ In fact the ILO's criteria of small firm size and ours of lack of registration are similar in motivation conceptually and lead to a great deal of overlap. The vast majority of micro-firm owners and their employed are, in fact, not covered. However, 5-7\% of the workforce in firms of over 10 workers also report being without coverage. Because we are interested in the entire universe of uncovered workers and prefer not to exclude this category from our analysis we include this group in the "informal salaried." On the other hand, there is also a certain attraction to dividing the sample into informal small firms and those who work for them so as to better understand how much of employment dynamics may, in fact, be due to small frm dynamics. We run the analysis both ways and the conclusions are identical in essence.

More specifically, owners or self-employed are not obliged to pay social security contributions for themselves, so we in fact consider informal self-employed those selfemployed and owners of micro-firms (less than 6 employees) with no social security contributions, excluding professionals and technicians. Owners of medium or big firms

\footnotetext{
${ }^{9}$ The ILO defines informality as consisting of all own-account workers (but excluding administrative workers, professionals and technicians), unpaid family workers, and employers and employees working in establishments with less than 5. We have also computed all the calculations presented in this paper considering the informal salaried those workers in small firms who have no social security with extremely similar results.
} 
(more than 5 employees) and those professionals and technicians self-employed or with social security contributions are all considered formal. Since this group is relatively very small they are pooled together with the formal salaried employees to form a conglomerate formal sector that will be used in the remainder of the paper. Again, this has no qualitative impact on the results.

The remainder of the sample is divided into two non-employment groups identical to those in the advanced country literature: those out of the labor force, and the unemployed. The behavior or these two groups has also received substantial attention in the US literature and, while not the focus of our analysis, we document how similarly they behave in Mexico. Tables 1 and 2 retrieve the sector sizes and some worker characteristics for all five different sectors.

\section{Methodology}

Though the data are tabulated at discrete quarterly intervals, the subsequent analysis makes it preferable to model the transitions among sectors in a continuous time framework. We therefore assume that the observed discrete-time mobility process is generated by a continuous-time homogeneous Markov process. ${ }^{10} \mathrm{We}$ assume a homogenous Markov process $X_{t}$ defined over a discrete state-space $E=\{1, \ldots . . K\}$ where $K$ is the number of possible states (job sectors) a worker could be found in. The worker if observed at equally distanced points of time. With that information one can construct a discrete time transition matrix $P(t, t+n)$ where

$$
p_{i j}(t, t+n)=\operatorname{Pr}(X(t+n)=j \mid X(t)=i \text { for } t=0,1,2, \ldots, \text { and } n=0,1,2, \ldots
$$

The interpretation of $p_{i j}$ is simply, the probability of moving from state $i$ to state $j$ in one step $(n)$. Discrete time matrices are easily straight forward to compute as the maximum likelihood estimator for $p_{i j}$ is $p_{i j}=n_{i j} / n_{i}$, being $n_{i j}$ the total number of

\footnotetext{
${ }^{10}$ For early work in this tradition, see Flinn and Heckman 1982 a, b and 1983).
} 
transitions from state $i$ to state $j$ and $n_{i}$ the total number of observations initially in state $i$. As $n \rightarrow 0$, this gives rise to a $k$ x $k$ transition intensity matrix $Q$ where

$$
\frac{d P(t)}{d(t)}=Q P(t)
$$

whose solution is given by:

$$
P(t)=e^{t Q}
$$

where $Q$ is a $k \times k$ matrix whose entries satisfy

$$
q_{i j}=\left\{\begin{array}{c}
q_{i j} \in R^{+}, j \neq i, i, j=1, \ldots, K \\
q_{i i}=-\sum_{k=2, k \neq i}^{K} q_{i j} \leq 0, j=i,=i=1, \ldots K
\end{array}\right\}
$$

Thus, $q_{i j}$ elements can be interpreted as the instantaneous rates (hazard rates) of transition from state $i$ to state $j$. These must be seen as reduced form estimates combining both the disposition of workers to move to a different state as well as the available "spaces" in that state: a workers desire to take a certain job and the availability of that job, quits and fires etc.

In practice, the estimation of the continuous time transition matrix from is subject to two major difficulties. First of all, solution to equation 2 may not be unique. This is known as the aliasing problem. That is, it is possible for an observed discrete time matrix to have been generated by more than one underlying continuous matrix. On the other hand it is possible that none of the solutions obtained for $Q$ is compatible with the theoretical model expressed in equation 1 where the elements of $Q$ have to satisfy the set of restrictions captured in equation 3. This is known as the embeddability problem. 
Two main approaches have been followed by the literature to estimate the $Q$ matrix and draw statistical inference. ${ }^{11}$ Kalbfleisch and Lawless's (1985) maximum likelihood procedure estimates the elements of $Q$ using a quasi-Newton or scoring algorithm. The main drawback of this approach stems from the fact that if $P$ is not embeddable, then standard asymptotic theory no longer applies and inference using the maximum likelihood is not reliable. ${ }^{12}$

Geweke et al (1986), propose a Bayesian procedure for statistical inference on intensity matrices as well as any function of the estimated parameters by using a uniform diffuse prior which allows establishing the probability of embeddability of the discretetime matrix. The method consists of drawing a large number of discrete time matrices from a previously defined "importance function," assessing their embeddability and constructing confidence intervals of the parameters or functions of interests using only the posterior distribution of those matrices that turn out to be embeddable. This also provides a very natural way of assessing the probability of embeddability as the proportion of the embeddable draws. ${ }^{13}$ We follow this approach (see also Fougère and Kamionka 1992 a,b,c).

Additional useful inferences can be obtained from estimation of the intensity matrix. For instance, duration times in state $i$ can be shown to be distributed exponentially

$d_{i} \sim \exp \left(-q_{i i}\right)$,

allowing us to retrieve the mean duration time en each sector as

$$
E\left(d_{i}\right)=-q_{i i}^{-1}
$$

\footnotetext{
${ }^{11}$ For an excellent overview of this topic see Fougère and Kamionka (1992a)

${ }^{12}$ The reader is again referred to Fougère and Kamionka (1992a).

${ }^{13}$ The probability of embeddability of all instantaneous transition matrices is in the range between 1 and 0.98
} 
All the estimates that follow have been obtained using the Geweke (1986) Bayesian procedure. ${ }^{14}$

\section{Overview: The Mexican Labor Market, 1987-2002}

\section{Movements in employment shares}

We first focus at the evolution of each sector's share of the labor force across the 1987-2002 period that includes two recoveries, the 1995 crises, and the slow down in 2001. Figure 1 plots the unemployment rate and the employment share of formal and informal workers. ${ }^{15}$ Here we divide the period into 4 periods, broadly linking the evolution of the macro economy and the labor markets.

Period 1: Recovery (1987-1992). Recovering from a recession at the end of the late 1980's and the first years of the 1990's, we see a decreasing unemployment rate which hovers at very low levels of 3\% up to the beginning of 1992.

Period 2: Appreciation of the peso, economic slow down and crisis (1992-1996). The two years prior to the tequila crisis show a slow but continuous increase in the unemployment rate. This precedes the sudden spike of the "tequila crisis" which briefly catapulted the unemployment rate to a decade high of $7 \%$ in the $2^{\text {nd }}$ quarter of 1995.

Period 3: Recovery (1996-2001). A large devaluation of the peso and a strikingly rapid recovery of the economy returned the unemployment rate to its pre-crisis levels in a matter of months. This was partly due to a $35 \%$ fall in the real wage engineered by holding nominal wages fixed and allowing the devaluation-induced inflation to erode real magnitudes.

Period 4: (US Recession 2001). The 2001 slow down of the U.S. economy led to a minor slowdown in the part of the Mexican manufacturing sector oriented toward the

\footnotetext{
${ }^{14}$ We thank John Geweke for providing the code for the estimation.

15 The informal sector includes both informal self-employment and informal salaried workers.
} 
U.S. market but had relatively modest impact on the rest of the economy. Unemployment increased mildly around 1\% and growth resumed at a steady rate in 2002 .

Several points deserve mention. First, the share of the formal over total employment sector remained reasonably constant (with slight decrease) from 1990 to 1993 at around 58\% of the labor force after a slight decrease in 87-90 from around 60\%. Thereafter, however, it began a slide to $56 \%$ on the eve of the crisis before bottoming out at $54 \%$ by the third quarter of 1995 . After the devaluation, it began a sharp recovery, regaining its earlier highs by 2001 when it fell again slightly in the 2001 slowdown. There is thus no secular increase in informality visible across the period.

Second, these movements are largely mirrored by the movement of unemployment from 3\% in 1989 to $7 \%$ during the crisis and then again down to the lowest levels in the sample in 2001. In fact the correlation between HP de-trended series of unemployment rate and the share of formal employment is - 0.73 (See table A1).

In sum, just looking at the employment shares and the unemployment rates over the business cycle suggests a very traditional interpretation of the role of the informal sector as a shock absorber for the formal sector in times of crises and perhaps some kind of disguised unemployment. However, the procyclical movement in informality's share in the 1987-1990 period fits uncomfortably with this view and suggests an important missing part of the story.

\section{Changes in informality share and industry flows}

The share of informality in the labor force rises from 42\% in Q1 of 1991 to $46 \%$

in Q4 1995 (Figure 1). Similarly the immediate recovery after the crisis informality returns to its original level by the 1 quarter of 2001. Figure 2 asks whether the cyclical evolution of informality we observe over the period responds to increases in the intensity in informality within industries or transfers of workers from less informal intense sectors to more informal intense. Employment is disaggregated into 8 sectors: Agriculture, 
Mining, Manufacturing, Financial Services, Gas and Electricity, Hotels and Restaurants, Transportation and Communications, and Other Services.

A number of facts emerge. First, informality is mainly concentrated in Services, Hotels and Restaurants, and Construction, whereas manufacturing is highly formal with an informality level of around $20 \%$. Essentially informality is concentrated in nontradable goods.

The second remarkable fact is that during the crisis in 95 and to a lesser extent in the recession in 2001, informality within the major sectors (Manufacturing, Services and hotels and services) rose. Similarly the employment share of manufacturing declined during the crises and increased during the recovery. Services mimicked this behavior in the opposite direction. In order to quantify which of the two effects had a higher impact on the overall level of inequality we decompose the overall increase in informality as follows.

$$
\Delta I_{t}=\sum_{j} \Delta i_{t, j} E_{t, j}+\sum_{j} \Delta E_{t, j} i_{t, j}
$$

Where $I_{t}$ is the overall level of informality at time $t \Delta i_{t, j}$ is the increase in the level of informality between $\mathrm{t} 1$ and $\mathrm{t}$ in sector $\mathrm{j}$ and $\Delta E_{t, j}$ is the increase in the employment share of sector between $\mathrm{t} 1$ and $\mathrm{t}$ in sector $\mathrm{j}$. The first term of equation of equation 5 retrieves the within sector increase in informality whereas the second term captures the increase informality due to the shift of workers from low informal sectors to high informal sectors. The decomposition suggests that $91 \%$ in the increase in informality between 1991 and 1996 was due to within sector increases in informality. Symmetrically the reduction in informality from 1996 to 2001 was $90 \%$ due to reduction in the levels of informality within sector. This is consistent with the evidence found by Ramos and Ferreira for Brazil (2001) who report an increase in informality in Brazil, from $40 \%$ of the labor force at the beginning of the 90 to $50 \%$ by 2002. They argue that despite the 
tertiarization of the Brazilian Economy in the 90's, most of the increase (74\%) was explained by changes in the in the informality within industries. Goldberg and Pavcnik (2003) studying the effects of trade liberalization on informality in Brazil and Colombia argue that around $80 \%$ in Brazil and practically $100 \%$ in Colombia of the increases in informality are attributable to changes in the composition of formal vs. informal workers within industry.

\section{Gross Flows of Workers}

\section{Overall patterns of mobility}

Table 3 presents the summary of transition intensities through the workforce pooling the entire 1987 to 2002 sample. We make only a few observations here.

First, the transition intensities among sectors are estimated with a high degree of precision (standard errors beneath coefficient) and there are important and statistically significant differences across origin-destination pairs. Second, there is a high degree of mobility throughout the matrix and among sectors.

Third, there is substantial variance in rates of mobility as captured by duration across sectors. Duration in unemployment is very short, averaging under 1 quarter while inactivity (OLF) is roughly 3 times that, both consistent with high job finding rates in all employed sectors. Though transitions to one of the three sectors of employment occur both from inactivity and from unemployment, the probability is several times higher from the latter.

Among sectors of employment, informal salaried workers show the lowest duration at slightly over 1 quarter, informal self employed with roughly 4 quarters and formal salaried at roughly 8 quarters. These are partly driven by higher informal job separation rates into unemployment and inactivity: Informal salaried workers are three times more likely to transit to unemployment than their formal counterparts and are also 
more likely to leave the labor force. Job separation among self employed is slightly higher than formal sector (around $3.74 \%$ vs $2.96 \%$ ). These differences may be driven by both worker and job characteristics. Informal salaried workers are relatively younger and less educated and hence with less job attachment; informality is concentrated mainly in services which tends to show higher turnover rates; small firms show high mortality rates everywhere; the lack of regulation and employment protection for informal workers may facilitate separation. It is beyond of the scope of this paper to disentangle these effects.

Such a snap shot is, in essence, a series of reduced form coefficients that cannot shed much light on the behavior of the sectors by themselves. We now explore the time variation of the worker flows.

\section{Hazard rates and duration over the business cycle}

Figure 3 suggests that table 3 hides substantial variations in duration rates across the business cycle. Looking first at the different classes of employment, we find strong countercyclical movements in duration. The slowdown from 1992 to the peak of the crisis was characterized by an increase in duration of roughly $50 \%$ whereas the recoveries in 1987-90 and 1998-2001 saw significant decreases in duration of roughly 20\%. What is striking is the very high correlation of duration changes between the formal sector and self-employment and informal salaried. The correlation coefficients of the HP de-trended series are 0.79 and 0.75 respectively. This suggests that the factors determining turnover (i.e: macroeconomic conditions dictating quitting or firing) affect formal and informal jobs a similar fashion. Further, the correlation appears relatively stable across the cycle showing little difference if, for instance, we split the sample into periods of decreasing unemployment (1987-1991 and 1996-2001) and those of rising (1992-1995 and 2001).

Looking at non-employment sectors we observe the patterns now standard in the mainstream literature. Figure 4 suggests that duration in unemployment again is countercyclical, reflecting the ease of finding jobs during upturns. Duration in inactivity (OLF) is 
generally acyclical although it decreases sharply during the crises which may reflect an increase in search manifesting itself in the reduction in the size of the OLF sector and increase in the size of the unemployed sector. ${ }^{16}$

\section{Flows among job types: Formality-Informality}

These swings in duration are, of course, derived from the observed corresponding swings in separation rates and here again we find great similarities in behavior across the sectors. The probabilities of transiting between formality and the two sectors of informality (figure 5) suggest pro-cyclical patterns of job allocation across all sectors of employment and the movements are highly correlated within pairs of bilateral flows, especially in the case of self-employment and formality. For instance, de HP de-trended series of S-F and F-S transition rates, and I-F and F-I transition rates show correlations of 0.85 and 0.26 respectively. These patterns correspond closely to the pro-cyclical patterns in job-to-job flows observed in U.S. literature on job-to-job flows (Shimer 2005c) that are generally attributed to workers finding better jobs in tighter job markets, or when workers are involuntarily separated in the normal churning process but find another before entering the unemployment pool. They are less consistent with the informal sector being the disadvantaged sector in a segmented labor market which would imply negative correlation between these flows across the business cycle.

\section{Flows between Employment and Unemployment}

So far, little has emerged from either duration or cross sectoral flows to suggest any that the three sectors represent fundamentally different categories of employment. However, as discussed above, the development and mainstream literatures have put special emphasis on the interface of employment and unemployment/OLF and here we do find some differences.

\footnotetext{
${ }^{16}$ Our findings are consistent with those of Flinn and Heckman (1983) for the US that, in Mexico as well, OLF and unemployment are distinct labor market states.
} 
Figures 6 show the flows from each of the employment sectors into unemployment and inactivity. For all sectors, as found for the US by Blanchard and Diamond (1990) and Hall (2005), flows into inactivity are pro-cyclical whereas flows into unemployment are clearly countercyclical and dramatically so during the "tequila" crisis of 1995. Informal salaried workers do appear to show the largest spike in separations during the Tequila crisis, almost quadrupling, while self employed doubled and formal separations increased by only $50 \%$. Strikingly, this does not to be the case in the 2001 recession which was characterized by an increase in job separation in the formal sector but not in the self employed sector and relatively modestly in the informal salaried sector. The most plausible explanation is that this recession was not systemic as the 1995 crisis was, but mainly caused by the slowdown of the U.S. economy that affected primarily the largely formal manufacturing export sector in the north of the country (see Kaplan and Martinez 2004). This emphasizes the importance of sectoral shocks to understanding overall labor dynamics.

Drawing on these last two sections, it is critical to point out that the informal sector does not seem to be playing the same role as unemployment. The correlation of the HP de-trended flows from formality into unemployment, informal salaried and self employed work with respect to unemployment rate are 0.59 and -0.14 and -0.43 respectively.

\section{Job-Finding from Unemployment}

Figure 7 suggests that the different sectors of employment contributed differently to the cyclical evolution of unemployment in job finding as well. The job finding rate in the formal sector is highly pro-cyclical and very volatile (See table A1), fluctuating from 0.6 in the peak of the booms in 1989 and 1998-2000 to 0.2 in the nadir of the 95 crisis. This is also true for the job finding rate from inactivity. However, the job finding rate in the informal sector although noisy (especially in the informal salaried sector) is reasonably constant, including during the crisis, maintaining job finding probabilities of 0.6 and .2 for the informal salaried and self employed respectively. 
It is possible that these differing job finding behaviors are statistical artifacts arising from the changing composition of unemployment". For example, if in recessions the pool of unemployed workers shifts toward young uneducated workers, who generally have a high propensity to search in he informal sector, this could offset the "real" decrease in the job finding rate in the informal sector. Baker (1992) refers to this as the "heterogeneity hypothesis. Annex I explores shifts in the composition of unemployment along three dimensions- age, education and reason of unemployment- and finds no support for this view.

What drives the different cyclical job finding and destruction patterns?

Explaining the differences in job finding and job destruction rates between the informal and formal sectors is a task exactly analogous to the debate in the mainstream literature. The high volatility and procyclicality of the job finding rate in the formal sector parallels the patterns in the US that Shimer (2005a) and Hall (2005) argue raise doubts about some of the features of the original Mortensen-Pissarides search matching models: ${ }^{17}$ the volatility in labor productivity is not sufficient to generate the observed volatility in vacancy generation. Numerous modifications have been suggested to improve explanatory power- better modeling of the opportunity cost of employment, capital costs, and on the job search (see Mortensen and Nagypal 2005 for a review). However, following Shimer and Hall, much of the focus has been on wage rigidities that prevent wages from absorbing productivity shocks, as is the case in the original Mortensen-Pissarides formulation, and thus generate large changes in the profitability of opening a vacancy. On the separations side, rational firms taking a dynamic view of the employment relationship will generally not myopically engage in what Hall terms Keynesian sticky-wage inefficient-separations and hence firing should be relatively smoother across the cycle.

\footnotetext{
${ }^{17}$ Shimer argues that the poor predictions arise from the Nash bargaining assump tions that imply that most of the change in productivity over the business cycle is absorbed by increases in wages giving little room for firms to post new jobs.
} 
How much the Shimer-Hall sticky-wage efficient variant of the search model can really explain is hotly debated in the literature (See Mortensen and Nagypal 2005, Hornstein, Krussell and Violante 2005). It does, however, clearly resonate with traditional view in the development literature that, while in the informal sector wages are unencumbered by regulation and are flexible, the formal salaried sector is governed by some type of wage rigidity. Hence, while our analysis of the Mexican data is informed by the mainstream literature, by virtue of offering what would appear to be a quasicontrolled experiment- one sector affected protected by unions and minimum wage legislation, the other not- it can also potentially also shed some light on the mainstream debate.

Figure 8 plots relative wages of the two sectors relative to the formal sector $(\mathrm{I} / \mathrm{F}$, $\mathrm{S} / \mathrm{F}$ ) and offers some at least qualitative support for the Shimer/Hall view. The standard deviation of the cyclical component in wages (once detrended using a HP filter) in both the informal salaried and the self-employment sectors is $32 \%$ and $35 \%$ higher than in the formal sector respectively, consistent with there being greater wage rigidity in the latter. Both series move procyclically, increasing faster during booms, falling faster during the 1995 crisis. Of particular note is the rise in self employed/formal earnings in 1987-90, the concomitance of which with the relative expansion of self-employment relative to formal work suggests strongly that self-employment was, in fact, a desirable sector during this period. More central to the discussion, the great fall in relative earnings corresponds to the tremendous fall in the job finding rate in the formal sector after 1992 and during the crisis, a period when the informal job finding rates were essentially acyclical. Perhaps muddying support for Shimer's hypothesis, the IS/F wage ratio is essentially constant from 1987 to 1993 suggesting that these earnings were determined by similar market forces or perhaps by the labor pact, at the same time that IS job finding was behaving somewhat procyclically and formal job finding was essentially acyclical. 
The fact that there is a very high correlation between informality and wage flexibility on the one hand, and small firm size on the other, suggests that breaking out the data by firm size is necessary to get a full picture of what is happening. Figure 9 suggests that both small formal and large formal firms showed strong countercyclical job finding during the crisis while across all sizes, job finding in the informal sector was relatively acyclical or even mildly procyclical. Job finding probability appears to be more a function of the nature of the contract, than firm size per se.

The picture is muddied somewhat by the job separation series. Consistent with Davis et. al's focus, figure 10 suggests that job separations are in fact, largely driven by firm size with the aggregate finding of acyclical firings in the formal sector, being driven by the fact that most workers in formal firms are in large firms much as Boeri argued for the US. Smaller and medium formal firms are extremely countercyclical in their separations. This is perhaps consistent with smaller firms operating closer to Jovanovic's failure bound and hence either not surviving the downturn, or perhaps that lack of access to credit to smooth over difficult times leads smaller firms to practice Hall's inefficient Keynesian job separations. However, somewhat awkwardly, figure 10 shows that informal workers in firms of all sizes show extraordinarily high separation probabilities. This would seem to suggest that again, it is the contract that is determining firing behavior and, since, as figure 11 shows, relative informal formal wages in big firms are the most flexible, it may be less wage rigidities per se than other contractual regulations on firing that are critical (see Pries and Rogerson 2005 for a discussion). Alternatively, it may be that though these workers report that they are working in large firms, they in fact are contracted by intermediaries who are smaller firms and hire and fire as such.

In the end, the differences in job separation and job findings in the formal vs informal sectors will involve both issues of firm size and contractual issues with an emphasis on wage rigidities. On the latter point, however, two caveats are in order. First, the mainstream literature has not converged on wage rigidities as being responsible for the common procyclical patterns in job finding that we see in both the Mexican formal 
sector and the US. Mortensen and Nagypal, for instance, even with wage rigidities and several other modifications to the Mortensen-Pissarides model can simulate only $40 \%$ of the volatility of the job finding rate and conclude that "In sum, the dilemma persists." This implies that the distinctive job creation behavior in the two sectors, and the implications that will be discussed in the next chapter for how the labor market adjusts, may involve far more than the traditional focus on formal sector rigidities. Second, even if wage rigidities turn out to be critical, the mechanism driving them may or may not include the usual considerations of unions or minimum wages. Kennan (2005) and Menzio (2005) both stress asymmetric information in wage bargaining process as inducing rigidities in wages with respect to productivity shocks.

\section{Informality: Alternative job type or disguised unemployment}

The patterns documented above suggest that, while probably very heterogeneous, overall, the informal sectors behave more like an alternative type of job than disguised unemployment. To recap:

1. In their countercyclical movements in duration and pro-cyclical rates of transition among job categories, the three sectors are remarkably similar to each other and to the patterns observed of movement among jobs in the US.

2. Clearly, this also implies that the informal sectors do not share the asymmetry of flows- procyclical flows into employment, countercyclical flows out- that unemployment shows. In fact, we find a high degree of symmetry of procyclical flows across the cycle, the most dramatic being the heightened flows in both direction between formal and self-employment during the 1987-91 recovery that led to an increase in the self employed sector exactly as relative earnings were increasing in that sector. This corresponds more to a positive shock to self employed intensive sectors rather than a draining of the unemployed pool. This is consistent with motivational responses of 
workers entering self-employment in 1992 that roughly $70 \%$ of the sector had entered for either reasons of greater flexibility or income (Maloney 1999).

3. This does not imply that there is no component of informality that serves as disguised unemployment. As a suggestive test, we plot the incidence of the response to the ENEU's question "Have you been looking for a job over the last two months" as a possible proxy for the degree of dissatisfaction with the current job coupled with the availably of alternative jobs. Figure 12 plots the proportion of workers who responded that they were looking for an alternative employment and who had not changed employment status from the quarter before. Search intensity is generally higher in the informal sector, perhaps, again, reflecting the relative youth of the informal salaried sector, although the magnitudes (and hence differences) are not large: in the upturns of mid-1990 and to 2000 search rates were equal across sectors at roughly 1-2\%. However, the share searching is strongly countercyclical implying that as the labor market becomes slack and job finding rates from all sectors decreases, the dissatisfaction increases. This is especially true in the informal sectors where the percentage searching for better jobs peaks at just under $7 \%$ during the crisis, a gap of slightly over $4 \%$ points over the formal sector, suggesting that, in fact, the sector contained more workers who were forced into bad matches by the crisis. This would make sense if, during the crisis, only the informal sector was hiring: though the job finding rate in the sector is reasonably acyclical, the fact that unemployment is increasing does imply that it is absorbing more unemployed as a share of the workforce than during booms.

\section{Accounting for Changes in Unemployment and Sectoral Shares with Gross Flows.}

Much of the motivation of the analogous US literature has been precisely to understand how changes in job-finding, job separation and job reallocation probabilities determine movements in the unemployment rate. We have the same interest in developing countries, and in addition, would like to understand the dynamics underlying the movements in sectoral shares across the business cycle, identified in section IV. 
Following Shimer (2005a) we construct the predicted steady state values of our five possible states for each period using the instantaneous transition probabilities generated above by solving

$$
\begin{aligned}
& o\left(q^{o u}+q^{o i}+q^{o s}+q^{o f}\right)=u q^{u o}+i q^{i o}+s q^{s o}+f q^{o f} \\
& u\left(q^{u o}+q^{u i}+q^{u s}+q^{u f}\right)=o q^{o u}+i q^{i u}+s q^{s u}+f q^{f u} \\
& i\left(q^{o i}+q^{u i}+q^{i s}+q^{i f}\right)=o q^{o i}+u q^{u i}+s q^{s i}+f q^{f i} \\
& s\left(q^{o s}+q^{u s}+q^{s i}+q^{s f}\right)=o q^{o s}+u q^{u s}+i q^{i s}+f q^{f s} \\
& f\left(q^{f o}+q^{f u}+q^{f i}+q^{f s}\right)=o q^{o f}+u q^{u f}+i q^{i f}+s q^{s f}
\end{aligned}
$$

and adjusting the resulting stocks so the corresponding shares sum to unity. Here, $q$ is the continuous intensity calculated in the immediately previous period and where $o, u, i, s$ and $f$ are the number of inactive, unemployed self employed, informal salaried and formal salaried workers. As table 4 shows, the predicted and actual series are highly correlated. For unemployment and the formal sector, the actual and predicted series match extremely well (correlations are 0.99 and 0.95 ).

Following Shimer (2005a), we then compute the size of the sector that would result if we allow one particular transition to vary (i.e. transitions from formal salaried work into unemployment) and leave all the other transitions constant at their average values during the period. This allows us to isolate the impact of a given type of gross flows on the aggregate sector sizes.

\section{Unemployment}

In the US unemployment literature, the issue has been whether the drivers of movements in the unemployment rate are changes in job separations or job finding probabilities. Figures 13 and 14 show the impact of changes of flows into and out of 
unemployment and formal sector in the unemployment rate and the relative size of the formal sector respectively.

Although our sample only covers one major crisis of the Mexican economy and a minor recession in 2001, figure 13 suggests that in response to the very deep shock represented by the Tequila crisis in 1995, job separation immediately jumps (panel 1), but only for a short period of time, and accounts for the rise in unemployment far more than does the job finding rate (panel k). The same appears true in the recession of 2001.

While this finding would seem overall to more closely correspond the Davis et. al's view than that of Shimer and Hall, it results from the fact that changes in informal separation rates drive the movements in the unemployment rate (panel h). Separations and reduced job finding in the formal sector have roughly equal, and relatively minor impacts (panels $\mathrm{i}$ and $\mathrm{j}$ ). The relatively constant job finding rate in the informal sectors has essentially no impact.

In sum, somewhat at odds with the view of the informal sector serving as a buffer for those separated formal sector workers who cannot afford to be unemployed, unemployment appears largely driven by separations from the informal sector. However, the fact that informality expands during the crisis, despite the increase in separations suggests a more complex role in the adjustment process that is revealed by looking more closely at the determinants of sector size.

\section{Accounting for movements in sectoral shares}

Consistent with the finding of little fluctuation in the formal separation rate, figure 14 confirms that reduced hiring in the formal sector drove the decline in the size of the formal sector on the way to the crisis and the reverse drove the subsequent recovery (panel 1). Panels $\mathrm{h}$ and 1 confirm that any increased flows out of the formal sector into informality or unemployment during the crisis did not account for the fall in the size of 
the formal sector, but it was rather the lack of access to formal jobs from the informal sector. This, again, contrasts with the idea that the informal sector provides the safety net for laid off formal workers. Correspondingly, the recovery of the formal sector was characterized by increased access to formal jobs.

Symmetrically, it is the fact that flows into formal employment fell by more than flows into unemployment that explains the expansion of the informal sectors (panel $\mathrm{j}$ ) during the crisis. In sum, the informal sectors did serve the role of a shock absorber of a sort during the crisis, just not in the traditional sense of absorbing separated formal workers. Rather, it expanded as accession to the formal sector became more difficult.

This story very conspicuously fails as an explanation for the expansion of selfemployment in the late 1980s and early 1990s as shown by the poor predictive power of informal- formal transitions across this period (panels e $\mathrm{g}$ and $\mathrm{i}$ ). Job creation and job separation are not major players. The action is rather found in the tremendous increase inflows from the formal salaried sector into self-employment which, if not partially offset by the increased flows in the reverse direction would have led to an even larger expansion. This is mirrored in figure 14 by the fact that inflows into formality from informality overpredict (panels $f, h$ and $j$ ) and the actual size of the sector and the reverse flows, by themselves, would have led to a major contraction Both sides tell the same story of enhanced reallocation among the formal and informal sector in the "boom" across this period. This is radically at odds with the idea that the informal sector is purely an inferior residual of a segmented labor market: as noted earlier, net flows are toward informality at exactly the same time that relative earnings are increasing there. Formal sector jobs were more abundant-the job creation rate increased- but net, workers preferred the better opportunities in the informal self employed sector. A broadly similar although less dramatic pattern appears for the informal salaried. Transitions into formality explain much of the rise of the sector across the crisis with perhaps some divergence in the early recovery and, again, an overprediction during this period of sector expansion with heightened transitions into the sector from formality. 
In sum, part of the informal sector does seem to play the role of unemployment in the Shimer-Hall world where job finding rate in the formal sector stops during recessions. Consistent with figure 5, transitions among all sectors are highly procyclical, but those from informality into formality slow down dramatically more during the recessions. However, an important part, dominant in the early recovery, behaves more like a small firm sector with the attractions that independence and possibly better money it offers. On the downside, small, young firms also have high failure rates and these appear to be exacerbated during downturns, much as Davis et al. suggest. It is this dynamic that explains movements in unemployment.

\section{Conclusions}

To summarize some of the findings, we find first that mainstream models are very applicable to Mexico's labor market, and that fows among all sectors of activity and flows from work into inactivity and unemployment all show cyclical patterns similar to those found in the US.

Second, in the formal salaried modern sector, we find the same patterns of procyclical job finding probability and moderate acyclicality in job separation rates as Shimer and Hall find in the US. However, we also find the reverse pattern among the small firm informal sector consistent with the perspective where job separations dominate the labor market dynamics: no strong cyclical patterns in job finding probabilities, but generally countercyclical separation patterns and a sharp spike in job separations during the 95 crisis. Given the large share of this sector in developing country labor markets, these contrasting patterns suggest that labor market composition indeed matters and that Boeri is correct that cross country comparisons need to bear this in mind.

Third, we find some support for the idea that patterns of job finding probability the US may be driven by wage rigidities. We do find a greater variance in informal 
earnings than in formal earnings that is consistent with the respective cyclical patterns of job finding probabilities in each sector.

Fourth, the striking similarity of cyclical patterns of duration in the formal and informal sectors, and of cyclical patterns of reallocation among them suggest that flows into the informal sector should be viewed, as a first approximation, much as job-to-job flows in the mainstream literature, and not as a fall into disguised unemployment. That is, consistent with standard matching models, more vacancies appear to arise in both formal and informal sectors during upturns and hence there is more rematching of workers and jobs across all sectors. Thus, while there may be a subset of workers queuing in the informal sector waiting for vacancies in the formal sector, it cannot be the dominant driver of the observed transitional patterns. In fact, during the recovery from the 1987 recession, gross flows between informal self-employment and formal salaried work rise in both directions with the net flow being toward informal self-employment, concomitant with a rise in relative self-employment/ formal salaried earnings. This positive comovement of relative sector size and relative earnings is not consistent with the standard segmented labor market view of the informal sector.

That said, the differing patterns of flows between each sector and unemployment, and the same Hall/Shimer procyclical job finding rate in the formal sector does create countercyclical expansion of informality. This, in a sense, can be seen as a partial revindication of the traditional safety net/segmentation view of informality, but in an updated and more complex guise: during downturns, job finding from unemployment in the formal sector stops, but in the informal sector it continues at a relatively constant rate. However, as in the mainstream literature, the mechanism behind the procyclical job finding in the formal salaried remains undetermined with classical wage rigidities a la Harris and Todaro being only one possibility and one that has shown limited predictive power in the analogous mainstream literature. Further, there is little evidence that the informal sector is a repository for separated formal salaried workers as is often thought: direct transitions from formality into informality fall across downturns as is the case with transitions among all sectors of activity. Finally, it is the countercyclical job destruction 
in the informal sector rather than either destruction or hiring slowdowns in the formal salaried sector that drives the cyclical movements in unemployment during the 1995 crisis.

Fifth, the differences in adjustment patterns between the 1995 recession and that in 2001 suggest that the nature of the shock, or at least to what sector it arrives is important. Here job destruction in the formal salaried sector, appears as the central driver in the rise in unemployment rates across the period. This is, at least, partially explained by the fact that the 2001 recession was linked to the US cycle and it was the exporting (mainly formal) sector that was particularly affected by it. In fact, the increasing job separation in the formal sector was the only flow apparently affected by the recession, job finding probabilities remained high and transitions between informality and formality were also high. 


\section{References:}

Antman, Francisco and David J. Mckenzie (2005) "Earnings Mobility and Measurement Error: A Pseudo-Panel Approach" mimeo, Stanford University.

Boeri, Tito (1996) "Is a Job Turnover Countercyclical?," Journal of Labor Economics, Vol. 14, No. 4: 603-625.

Davis, S.; R. J. Faberman, and J. Haltiwanger (2005);. "The Flow Approach to Labor Markets: New Data Sources, Micro-Macro Links and the Recent Downturn," Mimeo, University of Chicago, U.S Bureau of Labor Statistics and University of Maryland, forthcoming, Journal of Economic Perspectives.

Davis, Steven and J. C. Haltiwanger (1992); "Gross Job Creation, Gross Job Destruction and Employment Reallocation," Quarterly Journal of Economics 107(3):819-63

Davis, Steven and J. C. Haltiwanger (1999b); "On the Driving Forces behind Cyclical Movements in Employment and Job Reallocation," American Economic Review 89, no. 5, 1234-1258.

de Soto, Hernando (1989). The Other Path: The Invisible Revolution in the Third World. New York: Harper and Row.

Dunne, Timothy, Mark J. Roberts and Larry Samuelson (1988). "The Growth and Failure of U.S. Manufacturing Plants," Quarterly Journal of Economics 104(4): 671-698.

Ericson, Richard and Ariel Pakes (1992). "An alternative theory of firm \& industry dynamics", Cowles Foundation Paper 1041

Evans, David S. and Linda S. Leighton (1989). "Some Empirical Aspects of Entrepreneurship," American Economic Review 79(3): 519-535.

Fajnzylber, Pablo, William F. Maloney and Gabrial Montes Rojas (forthcoming) "MicroFirm Dynamics in Less Developed Countries: How Similar are The to Those in the Industrialized World? Evidence from Mexico" World Bank Economic Review,.

Flinn, Christopher J. and James J. Heckman (1983) "Are Unempoyment and Out of the Labor Force Behaviorally Distinct Labor Force States, Journal of Labor Economics $1(1): 28-42$.

Flinn, Christopher J. and Heckman, J (1982 a) "Models for the Analysis of Labor Market Dynamics," in Advances in Econometrics, R. Basmann and G. Rhodes, eds. Greenwich, Conn.: JAI 1982.

Flinn, Christopher J. and Heckman, J. (1982 b) "New Methods for Analyzing Structural Models of Labor Force Dynamics," Journal of Econometrics 18 (1982) 115-68. 
Fougère, Denis and Thierry Kamionka (2003), Bayesian Inference for the Mover-Stayer Model in Continuous Time with an Application to Labour Market Transition Data. Forthcoming in Journal of Econometrics.

Fougère, Denis and Thierry Kamionka (1992a) Individual Labour Market Transitions in Laslo Matyas and Patrick Sevestre The Econometrics of Panel Data: A Handbook of the Theory with Applications. Kluwer, Boston ch 29.

Fougère, Denis and Thierry Kamionka (1992b), Mobilité et Précarisation sur le Marché Français du Travail: Une Analyse Longitudinale Pour les Années 1986-1988. Economie et Prevision, 102-103: 157-178.

Fougère, Denis and Thierry Kamionka (1992c), Un Modele Markovien du Marché du Travail," Annales d'Economie et de Statistique, 27:501-8.

Geweke J, Robert Marshall and Gary A. Zarkin. (1986) "Exact Inference for Continious Time Markov Chain Models”. Review of Economic Studies 53(4). Pp653-69

Hagedorn, Marcus and I. Manovskii (2005); "The Cyclical Behavior of Equilibrium Unemployment and Vacancies Revisited," University of Frankfurt and University of Pennsylvania.

Hall, Robert (2005); "Employment Efficiency and Sticky Wages: Evidence Flows in the Labor Market," Review of Economics and Statistics 87(3)397-407.

Harris, John R., and Michael P. Todaro (1970). "Migration, Unemployment and Development: A Two-Sector Analysis," American Economic Review 60(1): 126-142.

Hornstein, A. ; P. Krusell, and G. L. Violante; "Unemployment and Vacancy Fluctuations in the Matching Model: Inspecting the Mechanism," Federal Reserve Bank of Richmond Economic Quarterly Volume 91/3 Summer 2005.

Jovanovic, Boyan (1982). "Selection and Evolution of Industry," Econometrica, 649-670.

Kaplan, David; G. Martinez and R. Robertson (2003); "Worker-and Job-Flows in Mexico." Mimeo, Instituto Tecnologico Autonomo de Mexico.

Kennan, John (2005); "Private Information, Wage Bargaining and Employment Fluctuations," University of Wisconsin-Madison.

Maloney, William F. (1999) Does Informality Imply Segmentation in Urban Labor Markets? Evidence from Sectoral Transitions in Mexico, The World Bank Economic Review, 13(2) 275-302. 
Maloney, William F. (2004) "Informality Revisited," World Development 32(7): 11591178.

Mazumdar, Dipak (1975) “The Urban Informal Sector” Working Paper 211, World Bank, Washington, DC.

Menzio, Guido (2005); “High-Frequency Wage Rigidity,” Northwestern University.

Mortensen, Dale and E. Nagypal (2005); "More on Unemployment and Vacancy Fluctuations," Northwestern University.

Pries, Michael and R. Rogerson (2005); “ Hiring Policies, Labor Market Institutions, and Labor Market Flows," Journal of the Political Economy, Vol 113, No 4.

Sethuraman, S.V. 1981 The Urban Informal Sector in Developing Countries. Geneva:International Labor Office

Shimer, Robert (2005a); “Reassessing the Ins and Outs of Unemployment," University of Chicago.

Shimer, Robert (2005b); "The Cyclical Behavior of Equilibrium Unemployment and Vacancies," American Economic Review, 95(1):25-49.

Shimer, Robert (2005c) "The Cyclicality of Hires, Separations, and Job to Job Transitions". Federal Reserve of St. Louis review, July/August. 87 (4), pp. 493-507.

Tokman, Victor, E. (1978) "An Exploration into the Nature of the Informal-Formal Sector Relationships.” World Development 6(9/10):1065-1075.

Yashiv, Eran (2005); "Evaluating the Performance of the Search and Matching Model," Tel Aviv University . 


\section{Annex I. Compositional impacts on the job finding rate}

Figures A1 present the shares of unemployment of a number of division in all three categories. It seems clear for those pictures that there are no clear cyclical patterns in the age and educational composition of the sample. There seems to be a pattern of ageing and increasing educational attainments of the unemployment pool but nothing to suggest that they could be driving the results above presented.

It is not obvious this is the case for unemployment. A very clear cyclical pattern emerges from figure A1. Separations account for a greater proportion of unemployed in recessions than in booms. Both the 1995 crisis and the mild slow down of the economy in 2001 reflect a higher share of separations, which is consistent with the evidence presented by Davis et al. and Shimer (2005a) for the US economy. If laid-off workers are more attracted towards informality, this could be raising the informal matching rate and decreasing the formal matching rate accentuating the flat job finding rate in the informal sector and the volatile job finding rate in the formal sector.

We assess this possibility following Shimer(2005a) and looking at two different measures of job finding rate. We compute a measure of job finding rate that accounts for changes in the composition of the unemployment pool $\left(F_{t}^{\text {comp }}\right)$ and another one which captures the changes of the job finding rate of each group of workers leaving the unaltered the composition of unemployment pool $\left(F_{t}^{\text {real }}\right)$ :

$$
F_{t}^{\text {comp }}=\frac{\sum_{j} u_{t, j} \bar{F}_{j}}{\sum_{j} u_{t, j}} \text { and } F_{t}^{\text {real }}=\frac{\sum_{j} \bar{u}_{t} F_{t, j}}{\sum_{j} \bar{u}_{t}}
$$

Where $\bar{F}_{j}$ is the time average job finding rate of each group and $\bar{u}_{t}$ is the average number of $j$ workers in the unemployment pool. We calculate these two measures for If changes in the unemployment are the reason of the flat job finding rate in the 
informal sector we should observe a pro-cyclical $F_{t}^{\text {real }}$ and $F_{t}^{\text {comp }}$. If composition was the reason $F_{t, j}$ would behave pro-cyclically for each group so $F_{t}^{\text {real }} 1$ would a be procyclical. At the same time difference in $\bar{F}_{j}$ would generate a more volatile $F_{t}^{\text {comp }}$ as changes in the composition of $u_{t, j}$ occur over time. For the formal job finding rate the existence of this compositional effect would lead to a more volatile Fcomp (as changes in utj would be driving the volatility of the job finding rate in the formal sector and a less volatile Freal.

We present $F_{t}^{\text {comp }}$ and $F_{t}^{\text {real }}$ for the job finding rates of the formal and the informal sector in figures A1. It seems that the compositional changes in the unemployed do not account for the pattern found in the data. Both the $F_{t}^{\text {real }}$ and the $F_{t}^{\text {comp }}$ are acyclical for the informal sector, meaning that the job finding rate in the informal sector seems to be acylical for all the groups considered and although some of the groups have higher probabilities to match informal jobs (young uneducated) this does not have much of a quantitative importance.

In the formal sector $F_{t}^{\text {comp }}$ is a flat line which implies little quantitative importance (if any) of changes in unemployment pool composition. The high pro-cyclicality and volatility of the job finding rate in the formal sector is driven by changes in the changes in the probability of all unemployed groups to match formal sector jobs. Hence the data suggest that changes in the composition of the pool of job searches does not seem to be behind the job finding patterns found in each sector. 
Table 1: Shares of the the five employment sectors:.1987 and 2002

\begin{tabular}{|c|c|c|}
\hline & $\begin{array}{c}\text { Q1:1987 } \\
\text { Share }\end{array}$ & $\begin{array}{c}\text { Q4:2002 } \\
\text { Share }\end{array}$ \\
\hline Out of the labor force & 0.15 & 0.14 \\
\hline Unemployed & 0.03 & 0.03 \\
\hline Informal Self-Employed & 0.16 & 0.17 \\
\hline Informal Salaried & 0.16 & 0.17 \\
\hline Small Firms & 0.08 & 0.10 \\
\hline Big Firms & 0.08 & 0.08 \\
\hline Formal Sector & 0.47 & 0.47 \\
\hline Owners of Firms & 0.03 & 0.04 \\
\hline Employees & 0.44 & 0.44 \\
\hline Unassigned & 0.03 & 0.01 \\
\hline
\end{tabular}

Note:g the ENEU. Small firms refer to those with 5 of less employees. Big firms refer to firms with more than 5 employees. Owners of Firms in the formal sector also include those self-employed which claim to have social security contributions and those categorized as professionals and technicians.

Table 2: Characteristics of employed workers 1q1987 and 4 q2002

\begin{tabular}{ccccc|cccc}
\hline & \multicolumn{3}{c|}{ 1st Quarter 1987 } & \multicolumn{4}{c}{ 4th Quarter 2002 } \\
& Age & School & Hours & Wage & Age & School & Hours & Wage \\
Informal Self-Employed & 39.16 & 6.05 & 41.49 & 0.98 & 40.48 & 8.11 & 46.02 & 0.83 \\
& & & & & & & & \\
Informal Salaried & 29.13 & 7.01 & 41.14 & 0.74 & 31.62 & 8.53 & 45.16 & 0.62 \\
& & & & & & & & \\
Formal Sector & 33.53 & 8.64 & 43.05 & 1.00 & 35 & 10.54 & 46.08 & 1.00 \\
\hline \hline
\end{tabular}

Author's calculations using the ENEU. The table shows the mean age, years of schooling (school) weekly hours of work (Hours) and the relative average wage with respect to the formal sector. 
Figure 1: Unemployment and Snare of Formal Employment

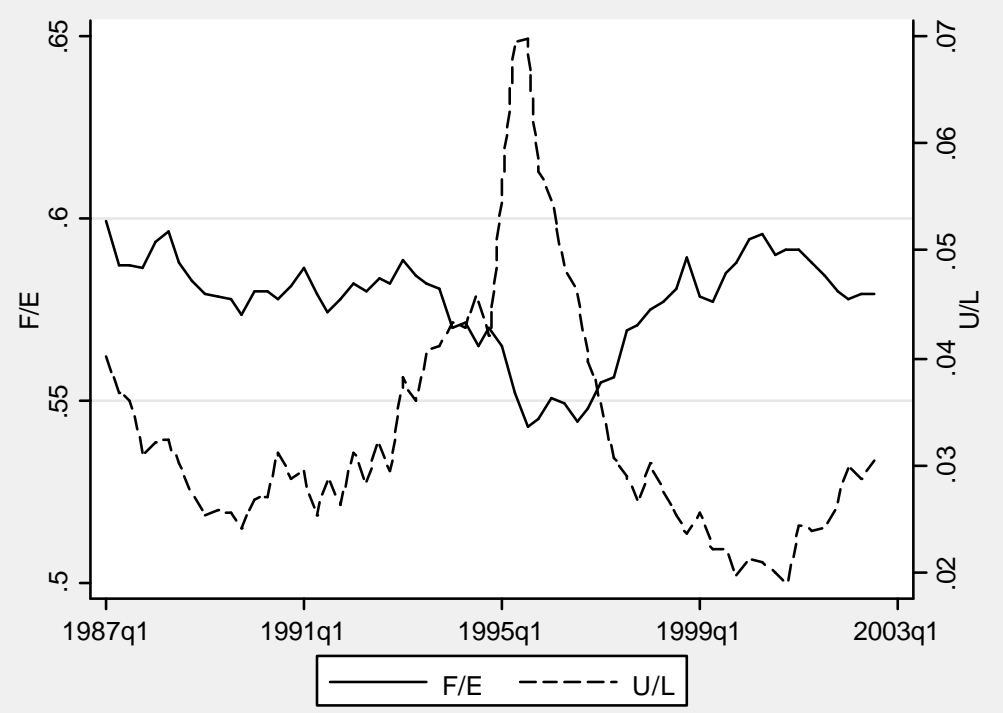

Note: Quarterly data from the National Urban Labor Survey (ENEU) 1987:Q1 to 2002:Q4. F/E is the share of formal employment constructed as number of formal workers over total employment. Unemployment rate (U/L) corresponds to number of unemployed workers over total labor force. 


\section{Figure 2: Employment Share and Informality Share by Industry}

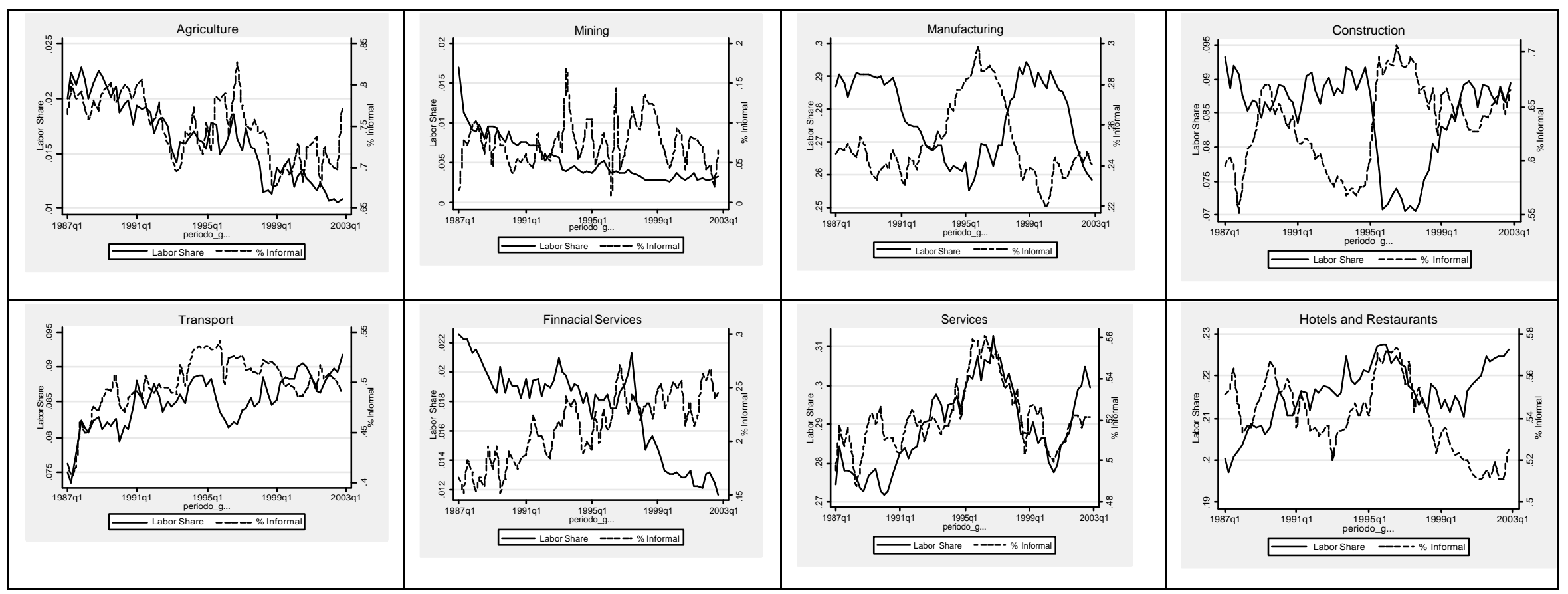

Note: Quarterly data from the National Urban Labor Survey (ENEU) 1987:Q1 to 2002:Q4. The share of employment of each industry is constructed as the number of total workers in the industry over total employment. The share of informality in the industry is constructed as the number of informal workers (both informal salaried and informal self-employed) over the total number of workers in the industry.. 
Table 3: Pooled continuous time intensity matrix 1987-2002.

\begin{tabular}{cccccc}
\hline & OLF & $\mathrm{U}$ & $\mathrm{SE}$ & $\mathrm{IS}$ & $\mathrm{F}$ \\
OLF & -0.2956 & 0.1225 & 0.0618 & 0.0688 & 0.0424 \\
& 0.0013 & 0.0012 & 0.0007 & 0.0008 & 0.0006 \\
$\mathrm{U}$ & 0.5228 & -1.5087 & 0.3475 & 0.3243 & 0.3141 \\
& 0.0053 & 0.0087 & 0.0045 & 0.0050 & 0.0040 \\
$\mathrm{SE}$ & 0.0367 & 0.0374 & -0.2758 & 0.1338 & 0.0679 \\
& 0.0004 & 0.0005 & 0.0009 & 0.0008 & 0.0005 \\
IS & 0.0960 & 0.1002 & 0.3737 & -0.8186 & 0.2487 \\
& 0.0013 & 0.0017 & 0.0022 & 0.0031 & 0.0018 \\
$\mathrm{~F}$ & 0.0153 & 0.0296 & 0.0463 & 0.0525 & -0.1438 \\
& 0.0002 & 0.0003 & 0.0003 & 0.0004 & 0.0005 \\
\multirow{2}{*}{ Duration } & 3.3826 & 0.6628 & 3.6259 & 1.2216 & 6.9545 \\
& 0.0145 & 0.0038 & 0.0119 & 0.0046 & 0.0241 \\
\hline
\end{tabular}

Note: Pooled instantaneous transition matrix computed using quarterly data from the National Urban Labor Survey (ENEU) 1987:Q1 to 2002:Q4 following the procedure by Geweke et al. (1986) outlined in section III. Computations are based on 10.000 Monte Carlo replications. Standard errors are reported in italics. OLF=Out of the Labor Force, $\mathrm{U}=$ Unemployment rate, IS=Informal Salaried, SE=Informal Selfemployed, F=Formal Sector. 
Figure 3: Mean duration in employment sectors

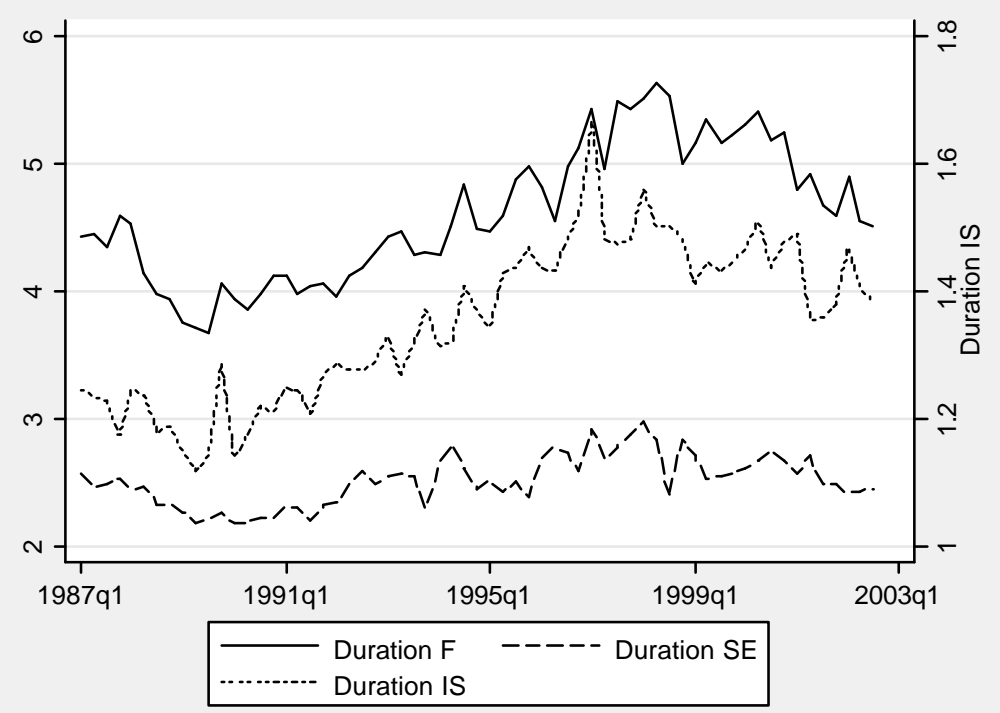

Note: Mean duration inferred from the continuous time transition matrix for each period using quarterly data from the National Urban Labor Survey (ENEU) 1987:Q1 to 2002:Q4 following the procedure by Geweke et al. (1986) outlined in section III. Computations are based on 10.000 Monte Carlo replications. OLF=Out of the Labor Force, U=Unemployment rate, IS=Informal Salaried, SE=Informal Self-employed, F=Formal Sector.

Figure 4: Mean duration in non-employment sector

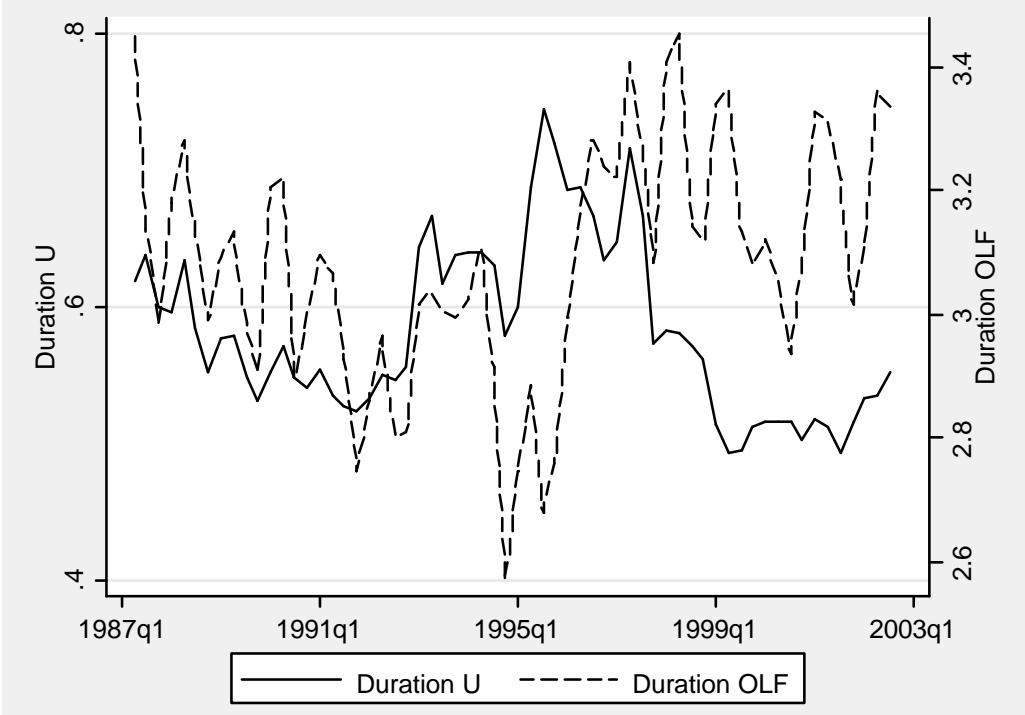

Note: Mean duration inferred from the continuous time transition matrix for each period using quarterly data from the National Urban Labor Survey (ENEU) 1987:Q1 to 2002:Q4 following the procedure by Geweke et al. (1986) outlined in section III. Computations are based on 10.000 Monte Carlo replications. The series have been smoothed using a 3 quarter moving average smoother. OLF=Out of the Labor Force, U=Unemployment rate, IS=Informal Salaried, $\mathrm{SE}=$ Informal Self-employed, F=Formal Sector. 
Figure 5: Transitions rates between formality and informality
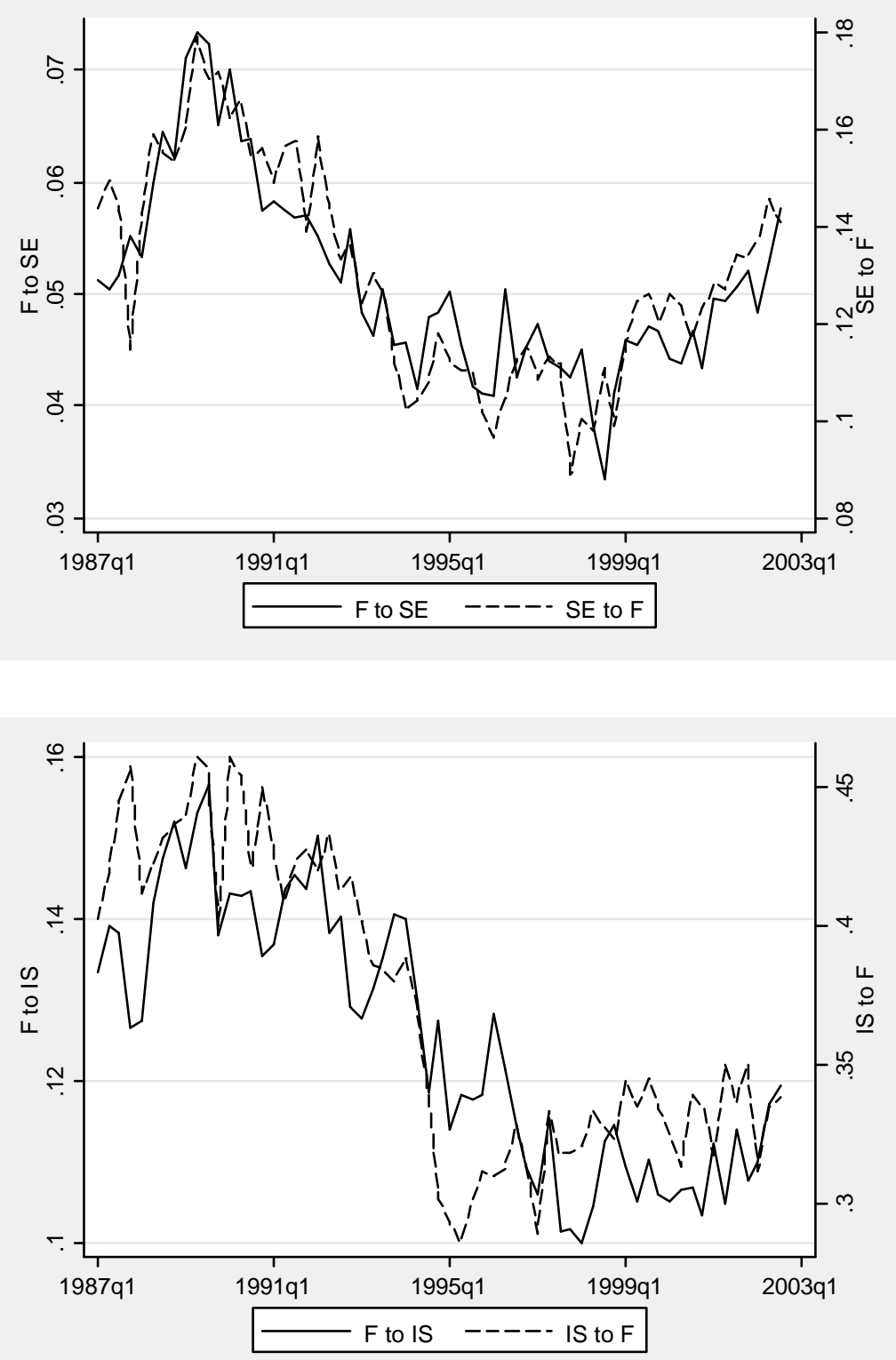

Note: Transition rates among sectors rates inferred from the continuous time transition matrix for each period using quarterly data from the National Urban Labor Survey (ENEU) 1987:Q1 to 2002:Q4 following the procedure by Geweke et al. (1986) outlined in section III. Computations are based on 10.000 Monte Carlo replications. OLF=Out of the Labor Force, U=Unemployment rate, IS=Informal Salaried, $\mathrm{SE}=$ Informal Self-employed, F=Formal Sector 
Figure 6: Job Separation rates
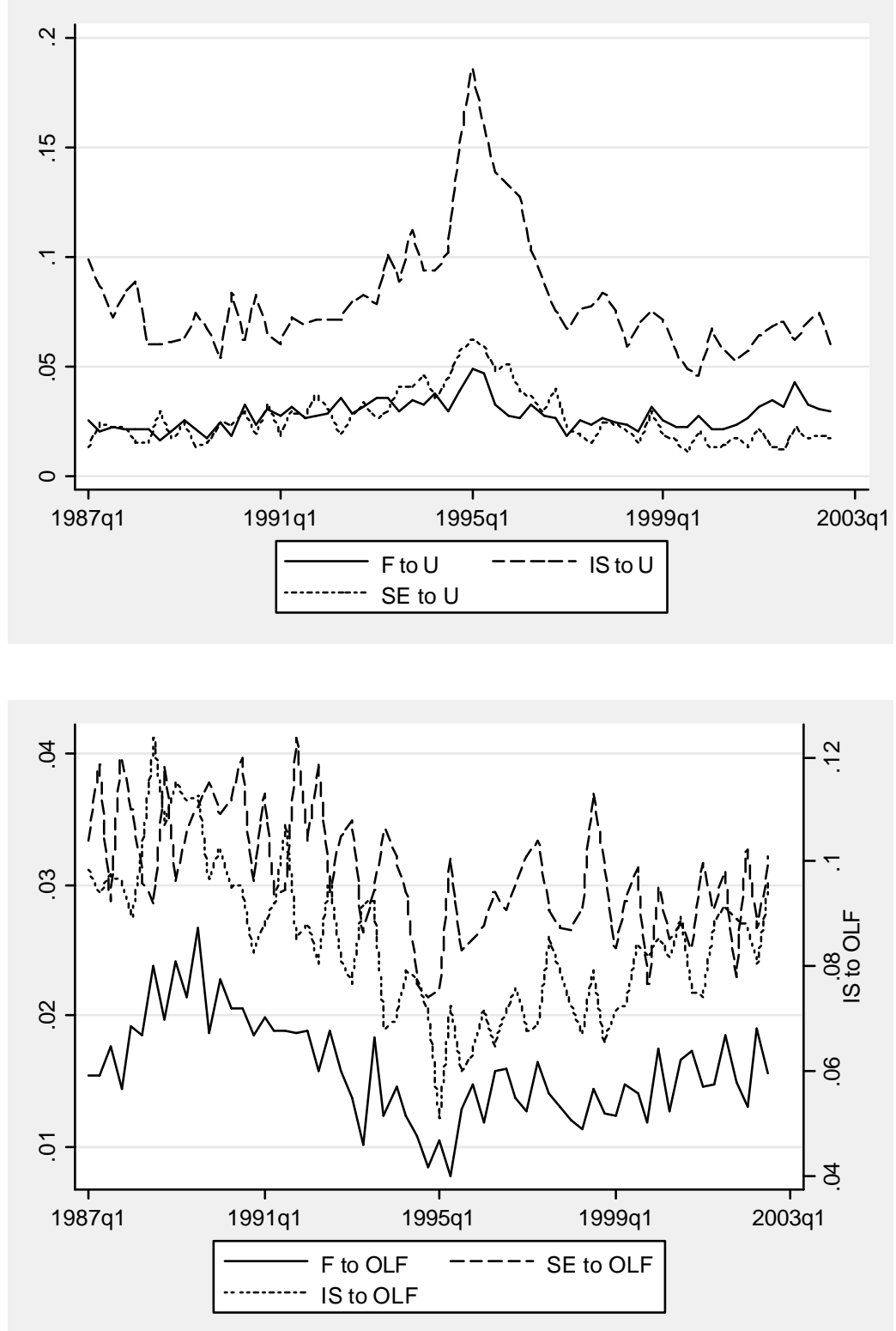

Note: Job separation rates inferred from the continuous time transition matrix for each period using quarterly data from the National Urban Labor Survey (ENEU) 1987:Q1 to 2002:Q4 following the procedure by Geweke et al. (1986) outlined in section III. Computations are based on 10.000 Monte Carlo replications. OLF $=$ Out of the Labor Force, U=Unemployment rate, IS=Informal Salaried, SE=Informal Selfemployed, F=Formal Sector 
Figure 7: Job Finding Rate
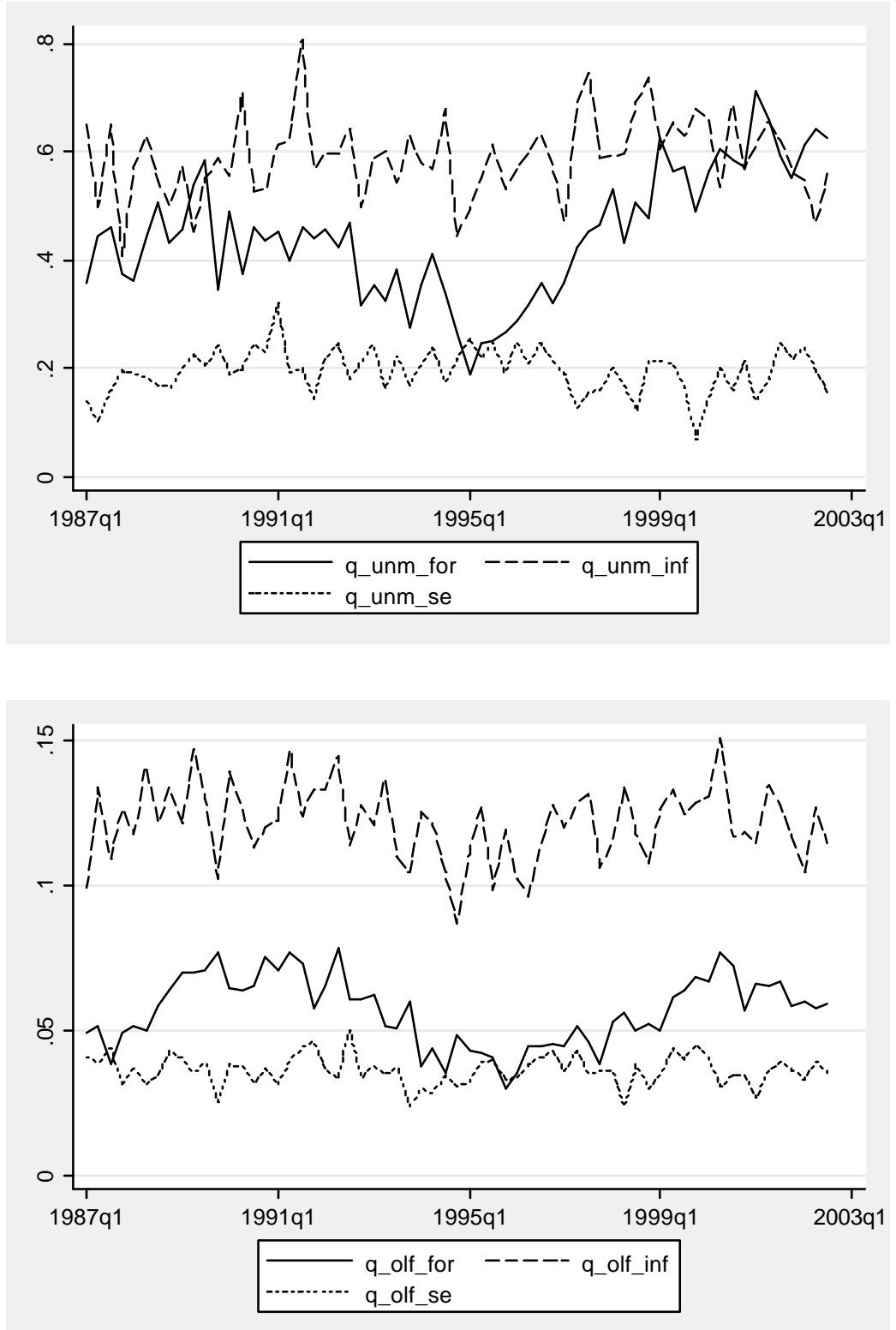

Note: Job finding rates inferred from the continuous time transition matrix for each period using quarterly data from the National Urban Labor Survey (ENEU) 1987:Q1 to 2002:Q4 following the procedure by Geweke et al. (1986) outlined in section III. Computations are based on 10.000 Monte Carlo replications. OLF=Out of the Labor Force, U=Unemployment rate, IS=Informal Salaried, SE=Informal Selfemployed, F=Formal Sector 
Figure 8: Relative wages between wages

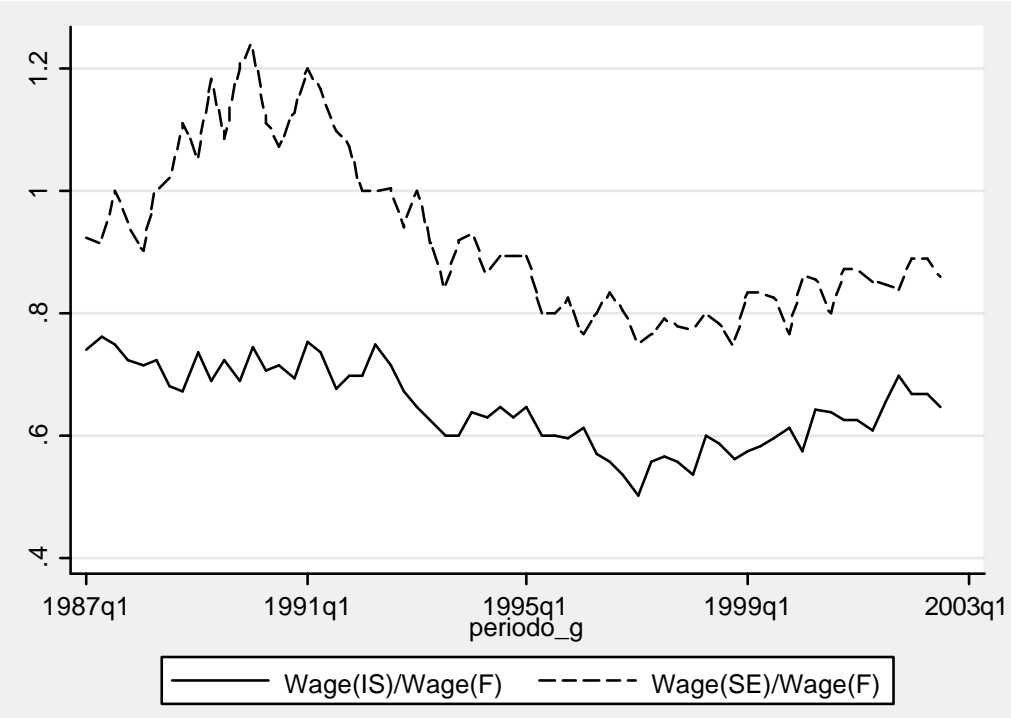

Note: Relative wages computed using the National Urban Labor Survey (ENEU) 1987:Q1 to 20 02:Q4.

IS=Informal Salaried, SE=Informal Self-employed, F=Formal Sector. 
Figure 9: Job Finding rates by Firm Size

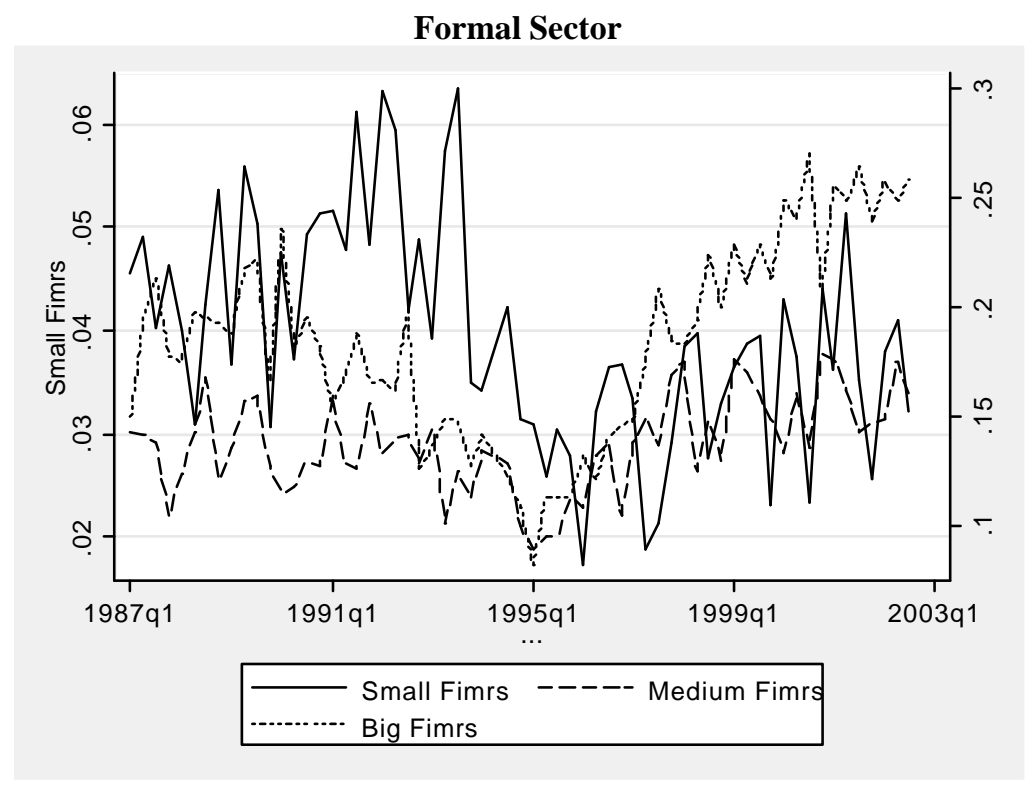

Informal Sector

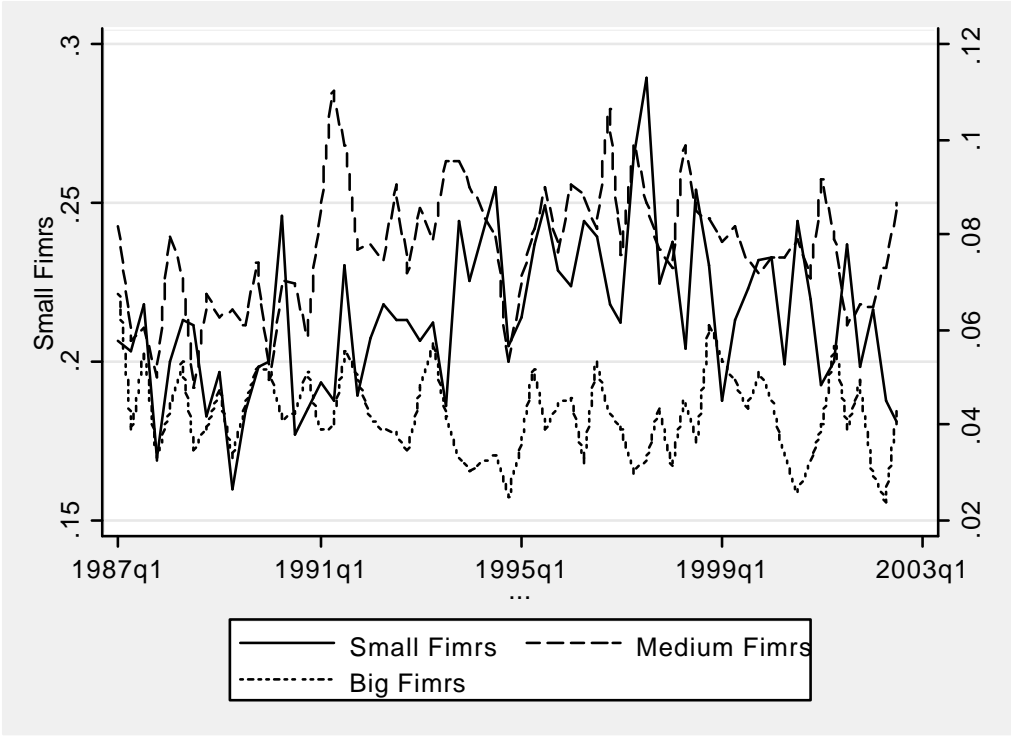

Note: Job finding rate inferred from the continuous time transition matrix for each period using quarterly data from the National Urban Labor Survey (ENEU) 1987:Q1 to 2002:Q4 following the procedure by Geweke et al. (1986) outlined in section III. Computations are based on 10.000 Monte Carlo replications.

Small Firms: less than 10 employees

Medium Firms: Between 10 and 250 employees

Big Firms: More than 250 employees 


\section{Figure 10: Job Separation rates by Firm Size}

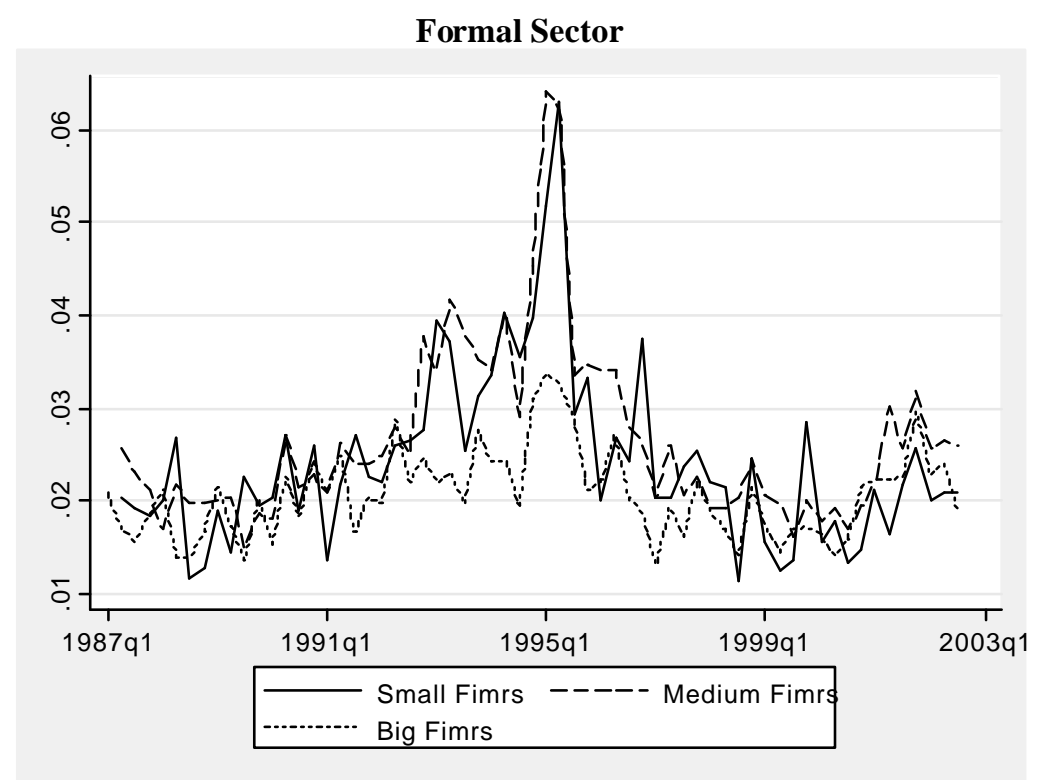

Informal Sector

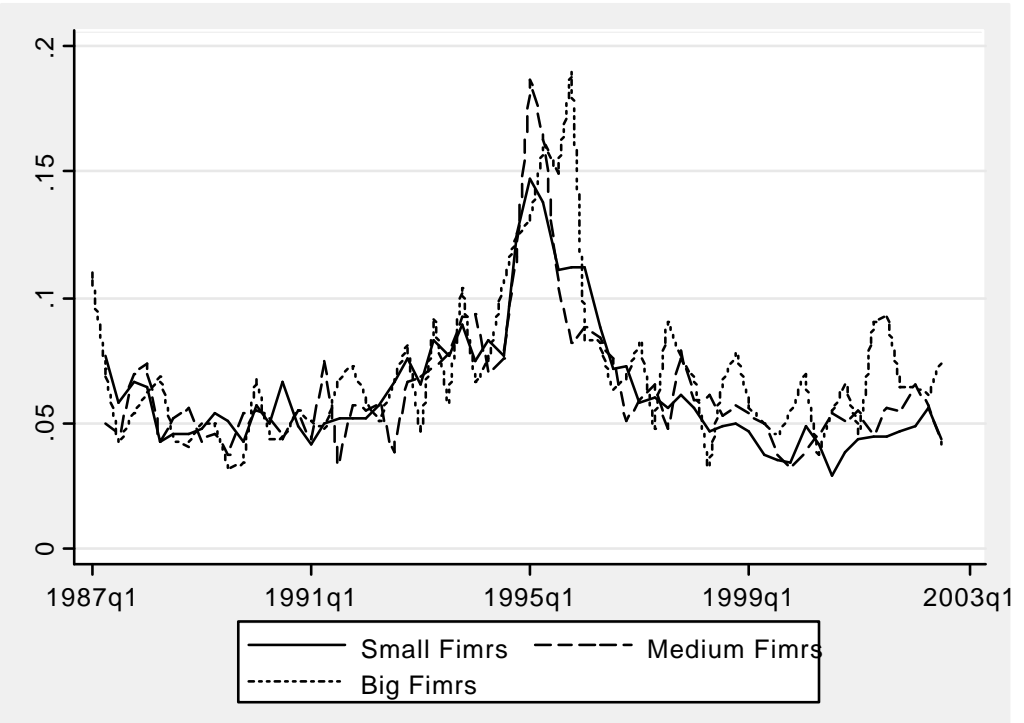

Note: Job separation rate inferred from the continuous time transition matrix for each period using quarterly data from the National Urban Labor Survey (ENEU) 1987:Q1 to 2002:Q4 following the procedure by Geweke et al. (1986) outlined in section III. Computations are based on 10.000 Monte Carlo replications.

Small Firms: less than 10 employees Medium Firms: Between 10 and 250 employees

Big Firms: More than 250 employees 


\section{Figure 11: Wage(I)/Wage(F) by firm Size}

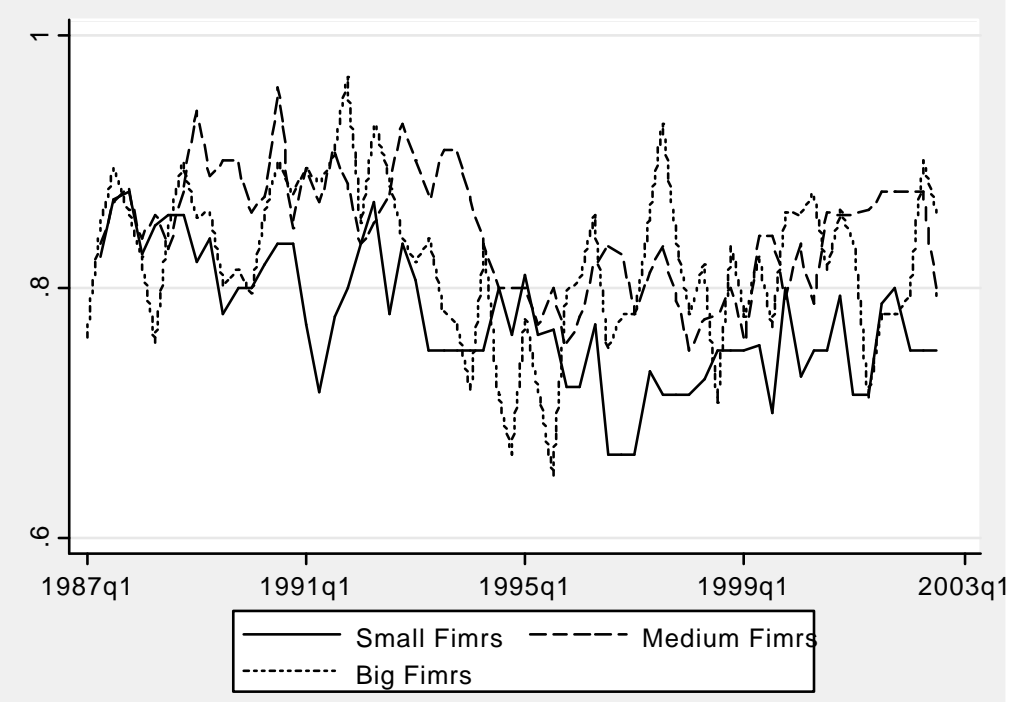

Note: Relative wages computed using the National Urban Labor Survey (ENEU) 1987:Q1 to 20 02:Q4.

IS=Informal Salaried, F=Formal Sector.

Small Firms: less than 10 employees

Medium Firms: Between 10 and 250 employees

Big Firms: More than 250 employees 


\section{Figure 12: Searching while Employed}

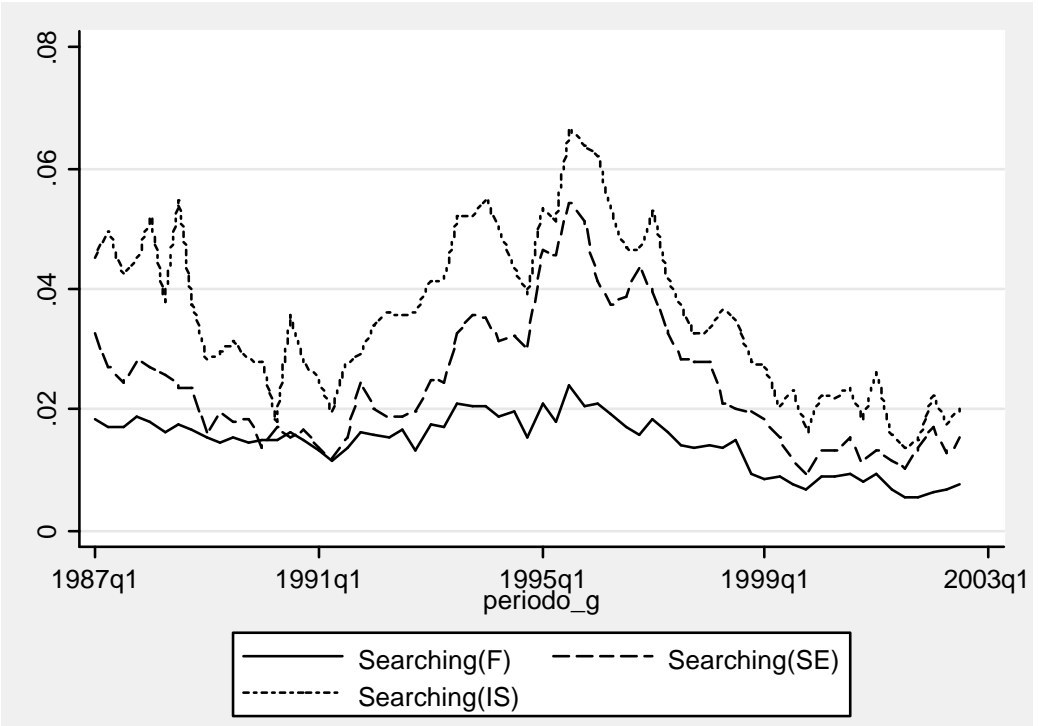

Note: Quarterly data from the National Urban Labor Survey (ENEU) 1987:Q1 to 2002:Q4. Searching(j) refers to the proportion of employed workers in sector $\mathrm{j}$ who claim to be looking for a new job and have not changed employment status in the previous quarter.

Table 4: Correlations between actual and expected size

\begin{tabular}{ccccc}
\hline OLF & U & IS & SE & F \\
0.89 & 0.99 & 0.81 & 0.91 & 0.95 \\
\hline \hline
\end{tabular}

Correlation of actual size of each sector and the steady state values predicted using equation 6 and the transition rates from the continuous time transition matrix for each period using quarterly data from the National Urban Labor Survey (ENEU) 1987:Q1 to 2002:Q4 following the procedure by Geweke et al. (1986) outlined in section III. Computations are based on 10.000 Monte Carlo replications. 
Figure 13: Unemployment rate and predicted

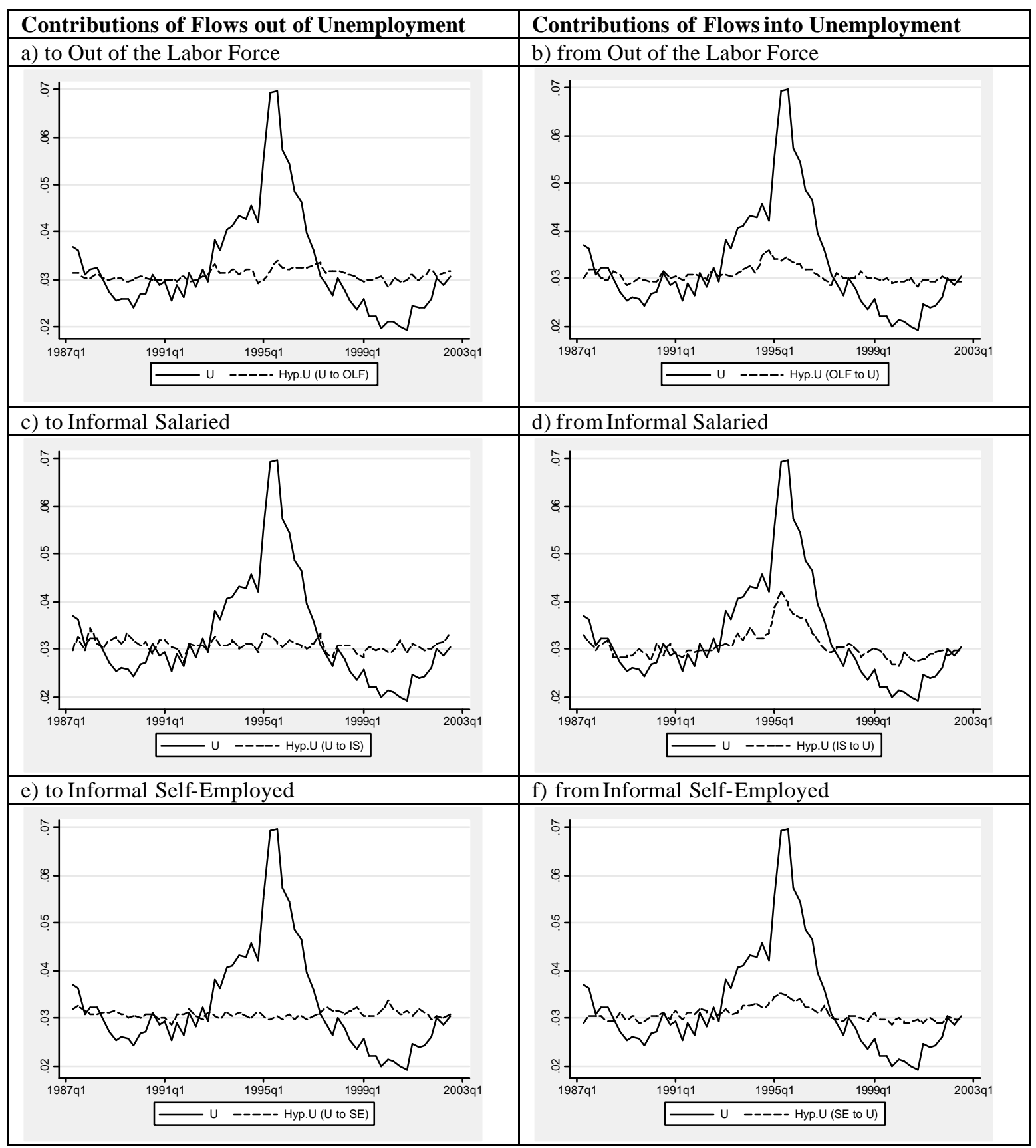




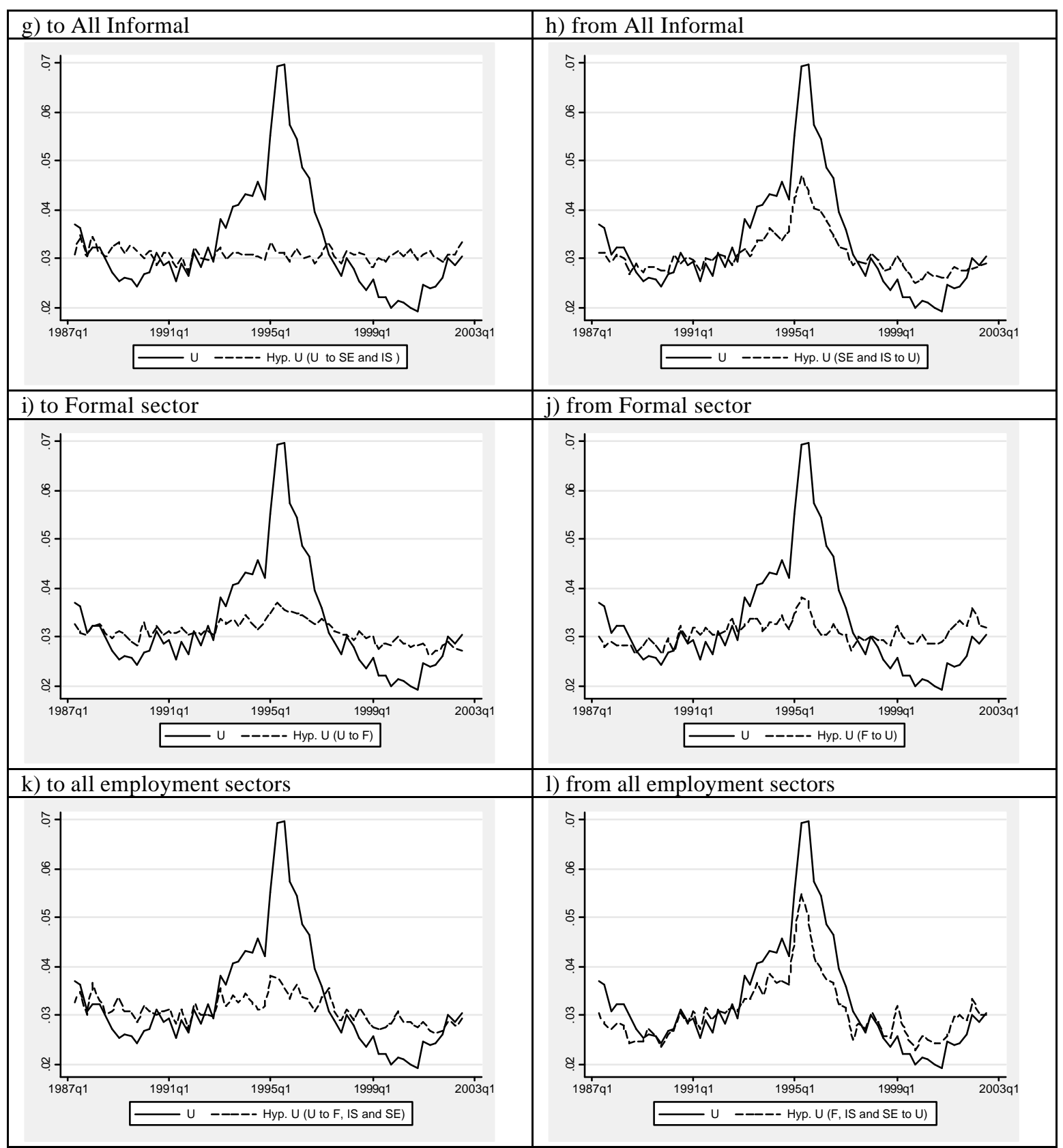

Note: U=Unemployment rate constructed using quarterly data from the National Urban Labor Survey (ENEU) 1987:Q1 to 2002:Q4. Hip U ( $i$ to $j$ ) corresponds to the steady state unemployment rate derived from equation 6 resulting of applying the 1987-2002 average transition rate of all the possible flows except for the transition rate from $i$ to $j$.

OLF=Out of the Labor Force, U=Unemployment rate, IS=Informal Salaried, SE=Informal Self-employed, $\mathrm{F}=$ Formal Sector. 
Figure 14: Size of the formal sector and predicted formal sector

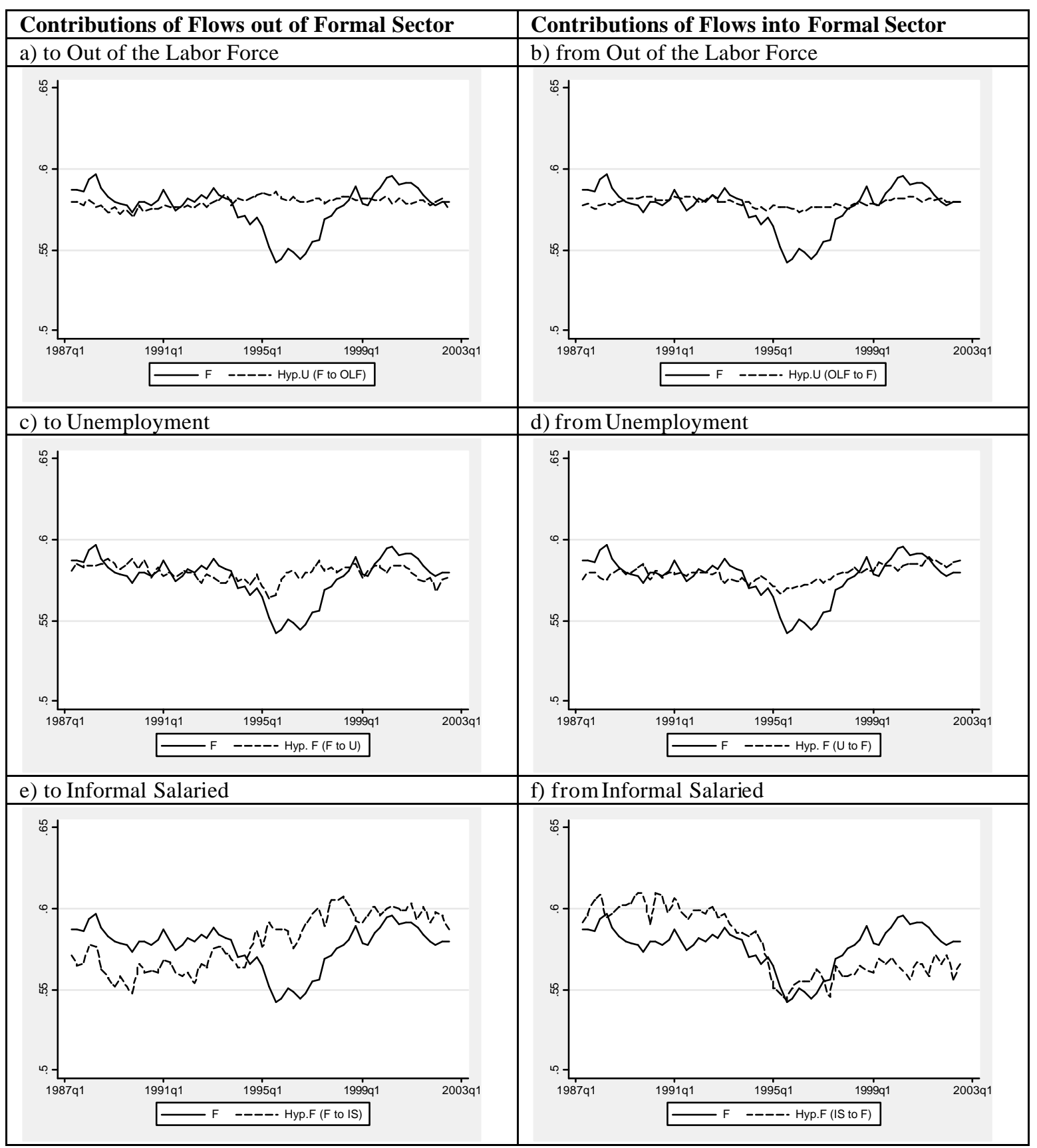




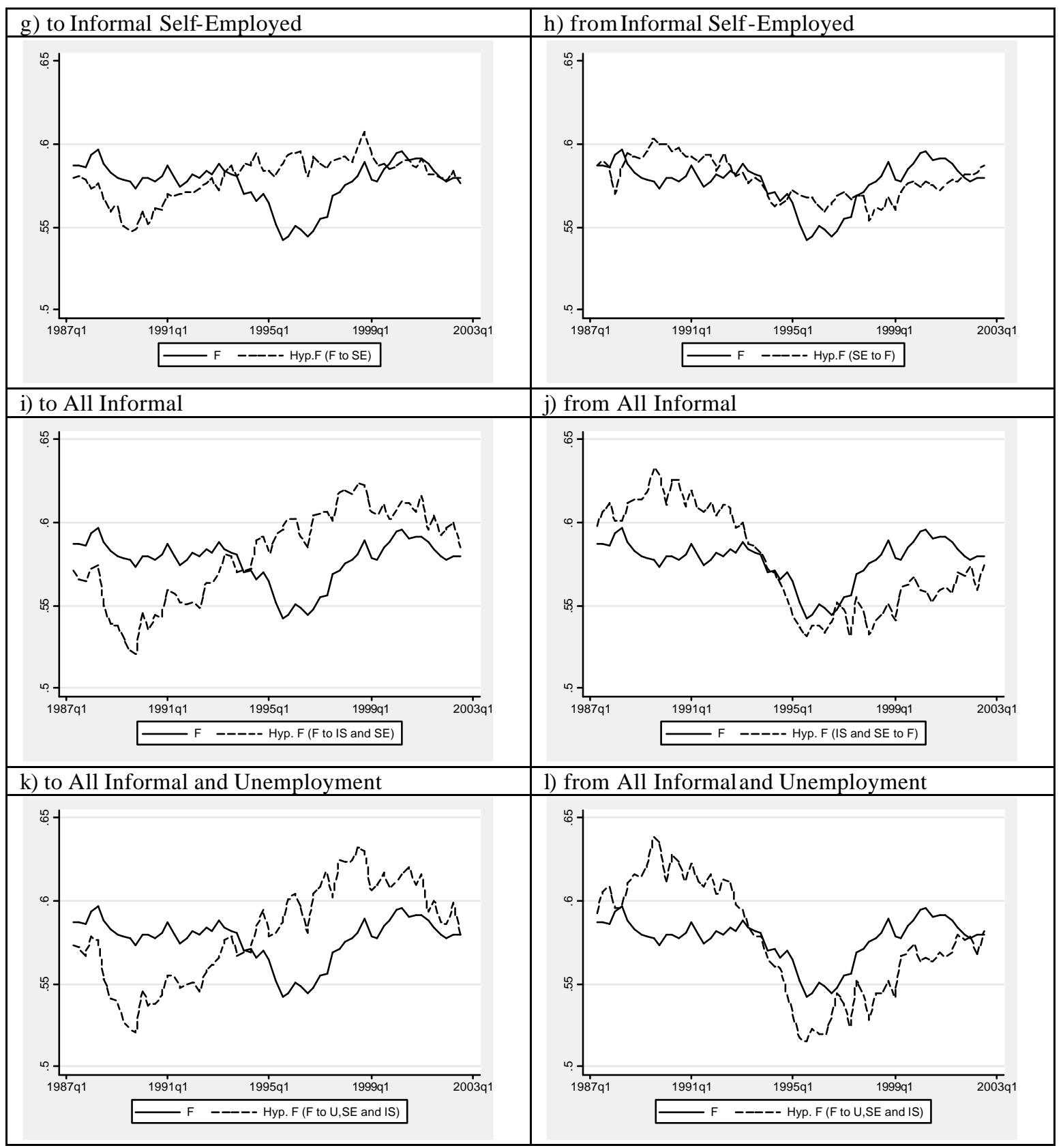

Note: $\mathrm{F}=$ Size of the formal sector is constructed using quarterly data from the National Urban Labor Survey (ENEU) 1987:Q1 to 2002:Q4. Hip F ( $i$ to $j$ ) corresponds to the steady state size of the formal sector derived from equation 6 resulting of applying the 1987-2002 average transition rate of all the possible flows except for the transition rate from $i$ to $j$.

OLF=Out of the Labor Force, U=Unemployment rate, IS=Informal Salaried, SE=Informal Self-employed, $\mathrm{F}=$ Formal Sector. 
Figure A1: Robustness checks of job finding probabilities.

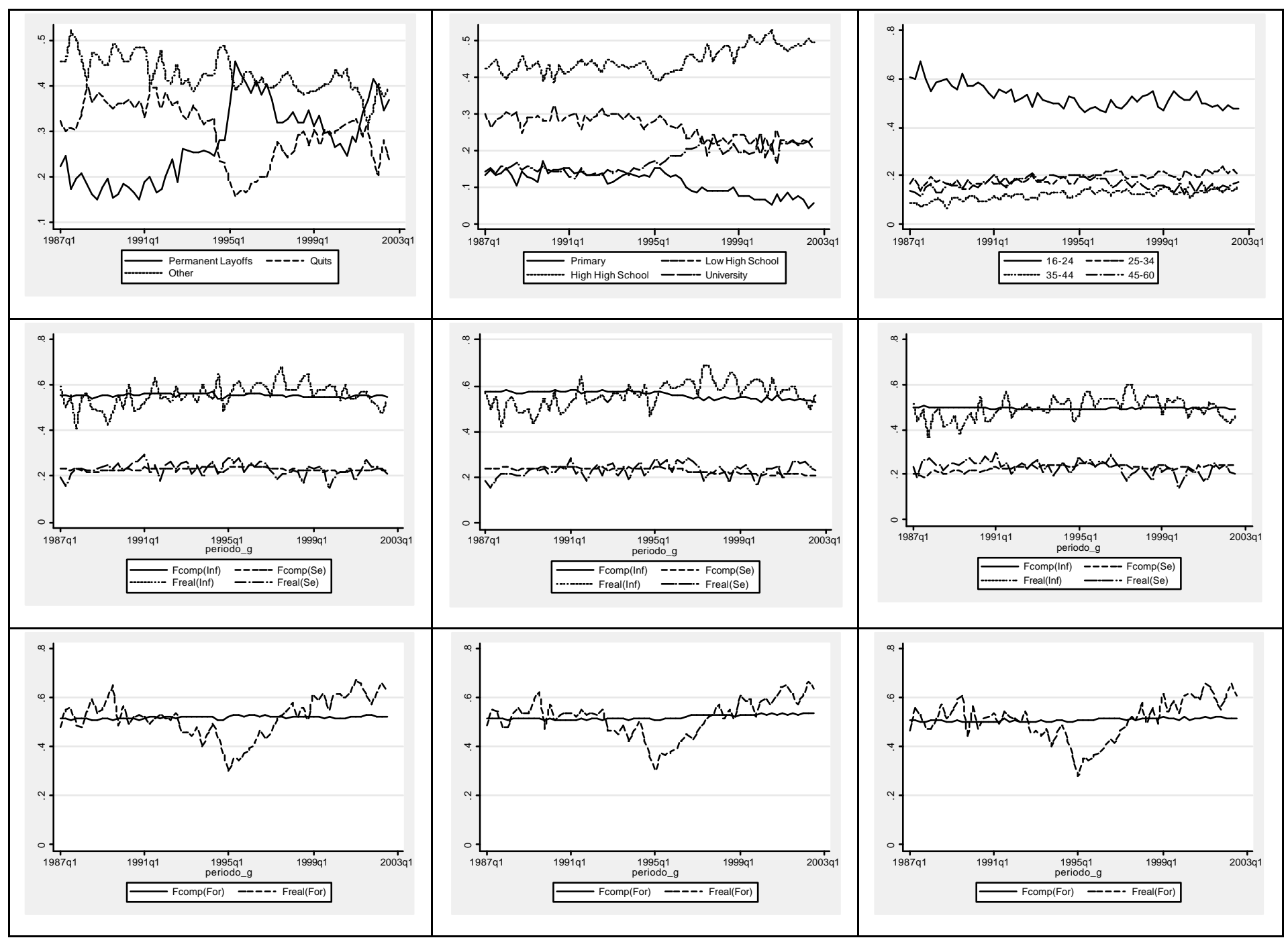

Note: Job finding probabilities inferred from the continuous time transition matrix for each period using quarterly data from the National Urban Labor Survey (ENEU) 1987:Q1 to 2002:Q4 following the procedure by Geweke et al. (1986) outlined in section III. Computations are based on 10.000 Monte Carlo replications. Fcomp and Freal are constructed following Shimer (2005) see appendix. 
Table A1: De-Trended Flows: Standard Deviations and Correlations.

\begin{tabular}{|c|c|c|c|c|}
\hline & & & Correlations & \\
\hline & $\begin{array}{l}\text { Standard } \\
\text { Deviations }\end{array}$ & U/AP & FOR/WAP & Output. \\
\hline Shares & & & & \\
\hline OLF/WAP & 0.0060 & -0.05 & -0.35 & -0.21 \\
\hline UNM/AP & 0.0100 & - & -0.80 & -0.70 \\
\hline FOR/AP & 0.0141 & -0.73 & 0.97 & 0.76 \\
\hline IS/AP & 0.1001 & 0.71 & -0.84 & -0.61 \\
\hline SE/AP & 0.0071 & 0.46 & -0.74 & -0.63 \\
\hline Flows & & & & \\
\hline OLF to $\mathrm{F}$ & 0.0104 & -0.77 & 0.61 & 0.60 \\
\hline OLF to INF & 0.0078 & -0.74 & 0.59 & 0.63 \\
\hline OLF to SE & 0.0033 & -0.14 & -0.03 & 0.12 \\
\hline OLF to UNM & 0.0234 & 0.79 & -0.50 & -0.55 \\
\hline UNM to F & 0.0812 & -0.90 & 0.74 & 0.57 \\
\hline UNM to IS & 0.0427 & -0.43 & 0.41 & 0.57 \\
\hline UNM to OLF & 0.0697 & -0.73 & 0.71 & 0.49 \\
\hline UNM to SE & 0.0275 & 0.38 & -0.45 & -0.33 \\
\hline F to IS & 0.0076 & -0.14 & 0.02 & 0.16 \\
\hline $\mathrm{F}$ to OLF & 0.0026 & -0.64 & 0.28 & 0.36 \\
\hline $\mathrm{F}$ to $\mathrm{SE}$ & 0.0060 & -0.43 & 0.11 & 0.17 \\
\hline F to UNM & 0.0052 & 0.59 & -0.34 & -0.41 \\
\hline IS to $\mathrm{F}$ & 0.0272 & -0.76 & 0.62 & 0.64 \\
\hline IS to OLF & 0.0093 & -0.70 & 0.50 & 0.36 \\
\hline IS to SE & 0.0150 & -0.54 & 0.36 & 0.16 \\
\hline IS to UNM & 0.0233 & 0.92 & -0.66 & -0.74 \\
\hline SE to $F$ & 0.0158 & -0.57 & 0.34 & 0.27 \\
\hline SE to IS & 0.0101 & -0.22 & 0.14 & 0.10 \\
\hline SE to OLF & 0.0026 & -0.51 & 0.26 & 0.44 \\
\hline SE to UNM & 0.0097 & 0.90 & -0.68 & -0.59 \\
\hline
\end{tabular}

Note: Transition rates among sectors rates inferred from the continuous time transition matrix for each period using quarterly data from the National Urban Labor Survey (ENEU) 1987:Q1 to 2002:Q4 following the procedure by Geweke et al. (1986) outlined in section III. Computations are based on 10.000 Monte Carlo replications. OLF=Out of the Labor Force, U=Unemployed, IS=Informal Salaried, SE=Informal Selfemployed, F=Formal Sector AP=Active Population, WAP=Working ages population. The series have been smoothed using a 3 quarter moving average smoother. De-trended using a HP filter with smoothing parameter $10^{5}$ 